
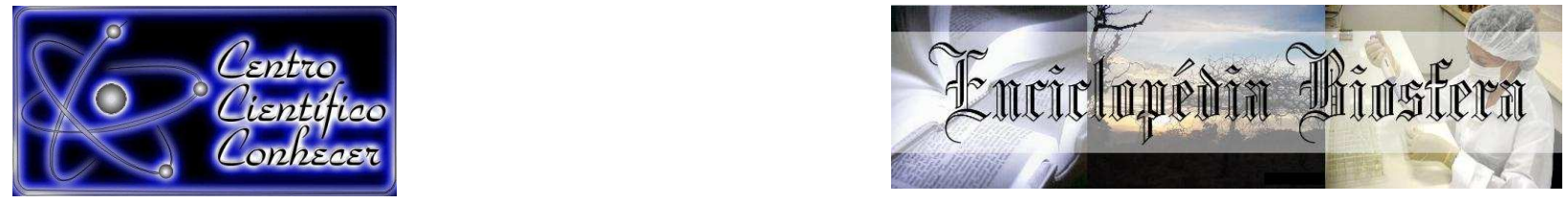

\title{
ASPECTOS GERAIS DOS FIOS DE SUTURA UTILIZADOS OU COM POTENCIAL APLICABILIDADE NA MEDICINA VETERINÁRIA
}

Saulo Humberto de Ávila Filho ${ }^{1}$, Luana Lamaro², Paulo José Bastos Queiroz ${ }^{3}$, Kamilla Dias Ferreira ${ }^{4}$, Luiz Antônio Franco da Silva ${ }^{5}$

1 Mestrando na Escola de Veterinária e Zootecnia da Universidade Federal de Goiás, Goiânia, Brasil (saulohumberto@gmail.com)

2 Mestranda no Instituto de Patologia Tropical e Saúde Pública da Universidade Federal de Goiás, Goiânia, Brasil

3 Mestrando na Escola de Veterinária e Zootecnia da Universidade Federal de Goiás, Goiânia, Brasil

4 Mestranda na Escola de Veterinária e Zootecnia da Universidade Federal de Goiás, Goiânia, Brasil

5 Prof. Dr. da Escola de Veterinária e Zootecnia da Universidade Federal de Goiás, Goiânia, Brasil

Recebido em: 08/09/2015 - Aprovado em: 14/11/2015 - Publicado em: 01/12/2015 DOI: http://dx.doi.org/10.18677/Enciclopedia_Biosfera_2015_088

\begin{abstract}
RESUMO
O fio cirúrgico é um material utilizado para contenção de estruturas orgânicas ou implantes, durante um procedimento cirúrgico. A diversidade de apresentação de tecidos e feridas bem como o desenvolvimento de vários fios de sutura, porém sem a universalização dos mesmos, geralmente colocam a equipe cirúrgica num interessante conflito a respeito do melhor material a ser escolhido. Portanto, ainda existem dúvidas sobre os fios de sutura utilizados na Medicina Veterinária. Nessas circunstâncias, acredita-se na necessidade de desenvolver pesquisas científicas com o propósito de diminuir, em parte, as dúvidas existentes sobre o tema. $\mathrm{O}$ presente estudo objetivou fazer uma revisão bibliográfica sobre os principais fios de sutura utilizados, ou com potencial, aplicabilidade na Medicina Veterinária priorizando suas classificações, características físicas, principais indicações e contra-indicações de modo a auxiliar o cirurgião nas tomadas de decisões sobre a escolha do material mais coerente com cada situação a ser enfrentada.
\end{abstract}

PALAVRAS-CHAVE: cicatrização, poliglactina, poliglecaprone, quitosana, fio farpado

\section{OVERVIEW OF SUTURE MATERIALS USED OR POTENTIALLY APPLIED IN VETERINARY MEDICINE: REVIEW.}

\begin{abstract}
The suture materials is used to approach organic structures or implants during a surgical procedure. There are many forms of tissue and wounds as well as the development of several sutures, but without the universalization of them, usually put
\end{abstract}


the surgical team in an interesting conflict about the best material choice. Therefore, there are still doubts about the sutures used in veterinary medicine. In these circumstances, it is believed the need to develop scientific research in order to reduce in part the doubts on the subject. This study aimed to do a review on the main sutures used, or with potential applicability in veterinary medicine prioritizing their classification, physical characteristics, main indications and contraindications in order to assist the surgeon choose the best material for each situation being faced.

KEYWORDS: barbed suture, chitosan, poliglecaprone, polyglactin, wound healing

\section{INTRODUÇÃO}

Os princípios básicos da cirurgia são a diérese, hemostasia e síntese. Esta última acontece ao final do procedimento cirúrgico e garante a integridade dos tecidos, seu correto posicionamento além de orientar e acelerar o processo de cicatrização da ferida. Atenção especial deve ser dispensada a essa etapa quando se tratar de tecidos isquêmicos e contaminados (IMPARATO et al., 1992); particularidades anatômicas, como a ausência de serosa no esôfago cervical e torácico; locais contaminados, como boca e intestino; contato frequente com bolo alimentar ou fecal; exposição à saliva devido as propriedades fibrinolíticas (SCHULTE, 1968); cavidade com possibilidade de aumento da pressão em seu interior, como bexiga e cavidade abdominal e ambiente com alterações de $\mathrm{pH}$ (IMPARATO et al., 1992). Em Medicina Veterinária, cuidados adicionais são requeridos para garantir e otimizar o processo cicatricial, devido à dificuldade do repouso pós-operatório e exposição da ferida a ambientes contaminados.

As suturas têm o objetivo de aproximar e estabilizar (KUMAR et al., 2013) as bordas das feridas por um tempo suficiente para recuperação da força tênsil natural. Dessa forma, favorecem a cicatrização, garantem o retorno da função do tecido e resultam numa aparência mais cosmética possível. Para efetuá-las, existe uma diversidade de fios com diferentes tamanhos, características físicas e de manuseio. Ainda que o fio de sutura auxilie a reparação tecidual, o contato com a ferida pode resultar em reação tecidual, isquemia, facilitar a absorção e disseminação de secreções e microrganismos, desencadear maior traumatismo, induzir formação de aderências, retardando e alterando o processo cicatricial (GREEMBERG \& CLARK, 2009). Além dessas possibilidades, a escolha equivocada do material de sutura pode comprometer severamente o processo de cicatrização e assim, o sucesso de todo o procedimento cirúrgico (KUMAR et al., 2013).

O processo de cicatrização e fechamento das feridas são eventos naturais que ocorrem independente dos fatores de risco. Este último, pode ser primário, primário retardado, secundário ou por fechamento terciário, sendo que as três primeiras são direcionadas e garantidas pela força tênsil de um fio de sutura. A cicatrização então ocorrerá em etapas ao longo de vários dias, sendo didaticamente dividida em etapas: inflamatória, proliferativa e de maturação. Assim, a ferida vai restabelecendo a força tênsil de maneira a construir um gráfico força vs tempo como uma curva sigmoide, sendo que o maior ganho ocorre durante a fase de reparação e o início da fase de maturação. O processo cicatricial pode ser avaliado, quantitativamente e qualitativamente no universo macro e/ou microscópico (BALLANTYNE, 1983).

Macroscopicamente, avalia-se quanto a presença de aderências, formação de fístulas, abcessos, deiscência da ferida, secreções e aparência 
cosmética. Para tanto, pode-se utilizar avaliação visual, ultrassonográfica, laparoscópica e termográfica. Na avaliação microscópica é possível avaliar a resposta tecidual quanto a celularidade (macrófagos, monócitos, linfócitos, fibroblastos), vasos sanguíneos e tecido conjuntivo (colágeno tipo I e tipo III) (BALLANTYNE, 1983). Para tanto são utilizadas técnicas variadas de coloração para avaliação histológica ou marcação de diversos anticorpos para avaliação imunohistológica. As feridas ainda podem ser avaliadas quanto a resistência mecânica, seja pela capacidade de resistir à tração ou insuflação com água ou gás (JIBORN et al., 1978).

O fio cirúrgico é um material utilizado para contenção de estruturas orgânicas ou implantes, durante um procedimento cirúrgico. Começaram a ser utilizados a mais de 4000 mil anos e desde 1970, com a aceleração do desenvolvimento estão em constante aprimoramento. Inicialmente foi produzido o categute, a partir do intestino de ovinos e bovinos, cujas características são: ser multifilamentar torcido e absorvível por proteólise. Na sequência foram utilizados os fios de seda e algodão, que são multifilamentares e inabsorvíveis. Dando continuidade, desenvolveram-se os fios de náilon e polipropileno, monofilamentares inabsorvíveis. Em seguida materiais absorvíveis multifilamentares trançados, como poliglactina e ácido poliglicólico e monofilamentares sintéticos como o poliglecaprone e polidioxanona foram avaliados. Nas últimas décadas, a inovação voltou a ser estrutural, desviando o foco dos fios lisos em detrimento dos fios farpados. Cada evolução teve a finalidade de minimizar a reação e trauma tecidual, melhorar o manuseio, reduzir o tempo cirúrgico, aperfeiçoar a distribuição da força, promover maior resistência à tensão e precocidade no tempo de absorção total, além de uma melhor padronização entre os iguais (GREENBERG \& CLARK, 2009).

A diversidade de apresentação de tecidos e feridas bem como 0 desenvolvimento de vários fios de sutura, porém sem a universalização dos mesmos, geralmente colocam a equipe cirúrgica num interessante conflito a respeito do melhor material a ser escolhido. Outro aspecto importante é a escassez de literatura sobre o tema, especialmente direcionada para a Medicina Veterinária, sendo os mesmos, quando presentes, associados a trabalhos humanos com modelos animais. Nesse caso, as informações disponibilizadas ficam muitas vezes superficiais. Acrescente-se que, as publicações mais confiáveis, com maior espaço amostral são disponibilizadas especialmente em relatos de casos em medicina. Tal impacto acentua-se quando o relato visa fios mais "modernos", sobretudo mais caros. Portanto, ainda existem dúvidas sobre os fios de sutura utilizados ou com potencial aplicabilidade na Medicina Veterinária. Nessas circunstâncias, acredita-se na necessidade de desenvolver pesquisas científicas com o propósito de diminuir, em parte, as dúvidas existentes sobre o tema.

O presente estudo objetivou fazer uma revisão bibliográfica sobre os principais fios de sutura utilizados na Medicina Veterinária, priorizando as classificações, características físicas, principais indicações e contra-indicações de modo a auxiliar o cirurgião nas tomadas de decisões sobre a escolha do material mais coerente com cada situação a ser enfrentada. 


\section{REVISÃO DE LITERATURA}

\section{Aspectos gerais sobre os fios de sutura}

Cada fio de sutura possui características peculiares que marcam o seu grupo, que devem ser consideradas durante a escolha. Acrescenta-se as particularidades das feridas, tipo de tecido, preferência do cirurgião e espécie animal. Ao negligenciar esses aspectos, o cirurgião pode desconsiderar embasamentos importantes que conferem segurança à síntese dos tecidos. Dentre os aspectos mais importantes relacionados aos fios de sutura é preciso considerar se o material é biocompatível, capacidade de absorção de fluidos, capilaridade, aderência, diâmetro e força tênsil. Também deve-se considerar a força do nó, elasticidade, plasticidade, memória, pliabilidade, coeficiente de atrito e reação tecidual (GREENBERG \& CLARK, 2009).

Considera-se biomaterial, qualquer estrutura, seja de origem natural ou sintética, que entra em contato com o corpo em qualquer momento, seja temporária ou permanente, na intensão de tratar, substituir ou incrementar algum tecido ou função orgânica (BRUCK, 1991). Biocompatibilidade é a forma e magnitude com que o corpo estranho e o tecido adjacente se influenciam (CHU et al., 1996). Absorção de fluidos é a capacidade absortiva quando totalmente submerso, porém quando parcialmente submerso denomina-se capilaridade. A absorção principalmente de soro cria um ambiente propício para a aderência e proliferação de microrganismos. Por sua vez, quanto maior a capilaridade, maior a disseminação de secreções e fluidos corpóreos entre os planos cirúrgicos, o que aumenta a probabilidade de instauração de processos infecciosos (GREENBERG \& CLARK, 2009). Outros aspectos também são importantes, como o poder de aderência do fio. Essa adesão é a facilidade de fixação de microrganismos na superfície do fio. Quanto maior a aderência, maior a chance de instauração de processos inflamatórios infecciosos (JAVED et al., 2012).

O diâmetro do fio também é uma característica a ser considerada. Os fios podem ser organizados quanto a espessura de acordo com dois sistemas de medidas, americano (USP) e europeu (métrico ou EP). O primeiro é escalonado de acordo com o número de zeros, variando de 12 zeros até três. Sendo que quanto maior o número de zeros, mais fino é o fio. O segundo padrão é mais simples, embora menos utilizado. Refere-se diretamente a espessura mínima do fio em décimo de milímetros. A espessura do fio está intimamente ligada a resistência mínima (Tabela 1), de forma que dois tipos de fios diferentes, porém com a mesma classificação de diâmetro, podem ter espessuras diferentes. Como exemplo, pode ter um fio absorvível dois zeros apresentando uma faixa de variação de espessura de 0,35 a 0,40 milímetros, enquanto um fio inabsorvível dois zeros apresentando uma faixa de espessura inferior, variando de 0,30 a 0,42 milímetros (GREENBERG \& CLARK, 2009). 
TABELA 1- Limites mínimo e máximo de diâmetro e força tênsil do nó correspondente a cada numeração USP ou EP

\begin{tabular}{ccccc}
\hline \multicolumn{2}{c}{ Sutura sintética } & \multicolumn{2}{c}{ Diâmetro $(\mathbf{m m})$} & $\begin{array}{c}\text { Força tênsil } \\
\text { do nó mínima } \\
\mathbf{( k g f )}\end{array}$ \\
\hline USP & EP & Mínimo & Máximo & 0,07 \\
8.0 & 0,4 & 0,04 & 0,049 & 0,14 \\
7.0 & 0,5 & 0,05 & 0,069 & 0,25 \\
6.0 & 0,7 & 0,07 & 0,099 & 0,68 \\
5.0 & 1 & 0,10 & 0,149 & 0,95 \\
4.0 & 1,5 & 0,15 & 0,199 & 1,77 \\
3.0 & 2 & 0,20 & 0,249 & 2,68 \\
2.0 & 3 & 0,30 & 0,339 & 3,90 \\
0 & 3,5 & 0,35 & 0,399 & 5,08 \\
1 & 4 & 0,40 & 0,499 & 6,35 \\
2 & 5 & 0,50 & 0,599 & \\
\hline
\end{tabular}

Fonte: adaptado de GREENBERG \& CLARK, 2009.

Ainda sobre aspectos gerais é preciso considerar a força tênsil do fio. Essa característica representa a força contínua, linear, necessária para a ruptura. É medida pelo tensiômetro (Figura 1). Quando implantado, recomenda-se atenção para alguns pontos importantes. Eventos rápidos como tosse, vômitos, exercícios e atividade extremas (traumas) geram maior força em um curto espaço de tempo, predispondo a quebra do biomaterial. Ruptura por sua vez é definida pela descontinuidade do fio, desde que não ocorra no local da tração. A região do nó é o ponto mais fraco da sutura (MUFFLY, et al., 2010), devido a redução do diâmetro do fio e a concentração da força tênsil em um só ponto (Figura 2) (GREENBERG \& GOLDMAN, 2013). 


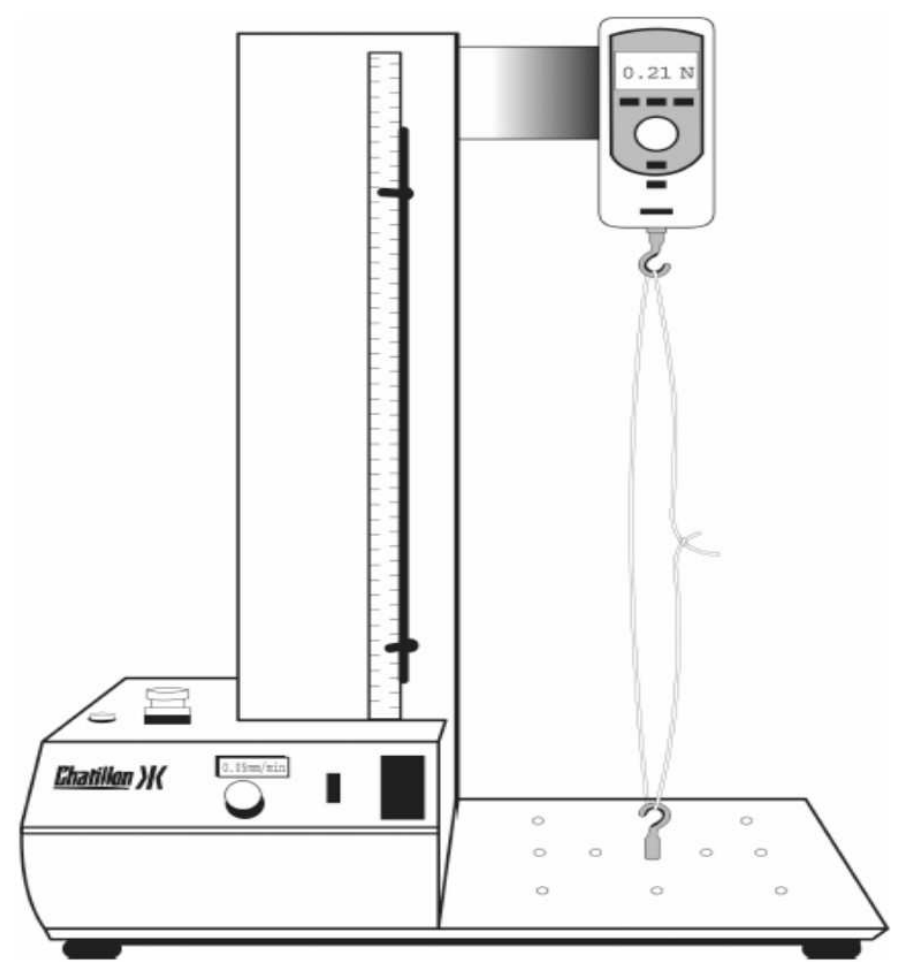

FIGURA 1- llustração esquemática de um tensiômetro.

Fonte: MUFFLY et al., (2010).

Ainda é preciso considerar a força do nó. Esta força é a segurança do nó em não se desfazer, não deslizar. Está intimamente relacionada com o coeficiente de atrito dos fios. Sendo assim, fios multifilamentares apresentam melhores segurança do nó. Com exceção quando utilizado fios metálicos, os quais mesmo monofilamentares apresentam a maior segurança conhecida. $O$ coeficiente de atrito é o arraste provocado ao se transpassar o tecido. Quanto maior o atrito, maior a dificuldade de transpasse e maior a chance de lesão do tecido. Os fios com multifilamentos apresentam os maiores coeficientes de atrito (GREENBERG \& GOLDMAN, 2013).

A reação tecidual é a capacidade de induzir uma resposta inflamatória tecidual, a qual inicia-se entre o segundo e o sétimo dia pós-implantação (SILVERSTEIN \& KURTZMAN, 2005). A reação é alterada de acordo com a composição, quantidade e duração do material, além da magnitude do trauma no momento do implante e aderência bacteriana. Desta forma, observou-se que materiais orgânicos absorvidos por proteólise e multifilamentares induzem reação tecidual de maior magnitude (DERNEL \& HANARI, 1993). 


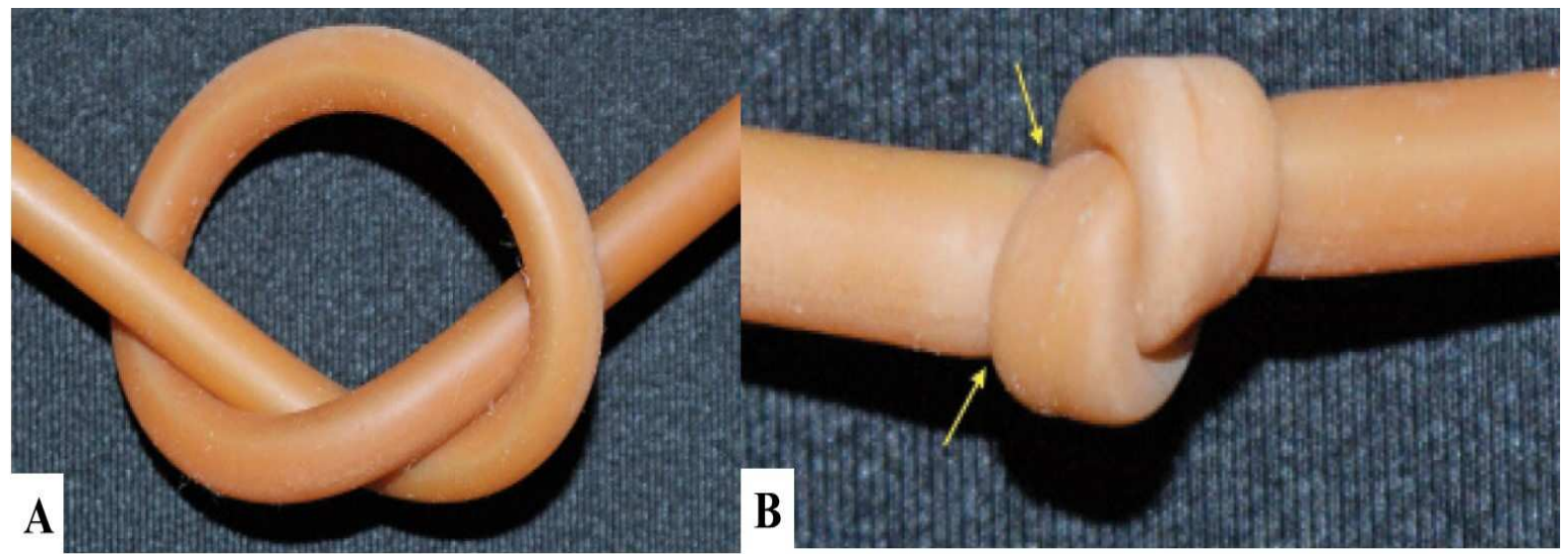

FIGURA 2- Redução do diâmetro da borracha de látex durante a confecção do nó. (A) - início da confecção do nó. (B) - nó apertado. (Seta) - redução do diâmetro e compressão da borracha de látex.

Fonte: GREENBERG \& GOLDMAN, (2013).

Elasticidade é a capacidade de retorno à forma original ao fio após este ser submetido a uma força de tração. É uma característica importante quando o fio for utilizado em articulações e tendões. A plasticidade é a capacidade de modelamento do fio, adquirindo novas formas. Quanto maior a plasticidade, maior a acomodação da sutura na ferida e menor as chances de ruptura das bordas. Denomina-se memória a tendência do fio em retornar a conformação anterior. Quanto maior for a memória, mais difícil é o manuseio e menor é a segurança do nó. Finalmente a pliabilidade é a facilidade de manuseio, facilidade de realizar a sutura. Geralmente os fios multifilamentares orgânicos detêm a melhor pliabilidade, sendo fio de seda detentor da melhor sensação de manuseio (LACERDA, 2013).

\section{PROPRIEDADES ANTIBACTERIANAS}

Idealmente os fios devem resistir à aderência das bactérias, prevenindo assim infecção de ferida. Essas propriedades podem depender da composição química, como é o caso do fio de quitosana, ou da adição de outros mecanismos antibacterianos (MASINI et al., 2011). Duas estratégias são mais comumente utilizadas em fios de sutura (HASAN et al., 2013); Revestimento passivo baseado em polímeros catiônicos que previnem a adesão, ou estratégias ativas que liberam substâncias com potencial bactericida, tal como a prata (DUBAS et al., 2011), peptídeos antimicrobianos (KAZEMXADEH-NARBAT et al., 2013) ou antibióticos (EDMISTON et al., 2006). Enquanto as estratégias passivas influenciam menos na biocompatibilidade, as ativas são mais eficientes. Entretanto, a toxicidade e o desenvolvimento de microrganismos resistentes as limitam (SERRANO et al., 2015).

Com o advento das técnicas microeletrônicas, foi disponibilizado o tratamento com o plasma de oxigênio. Esse tratamento consiste na exposição do fio a um feixe iônico, garantido por um campo elétrico de alta tensão e um ambiente sem pressão atmosférica. Como resultado cria-se micro ou nanotopografias na superfície dos fios, sem que ocorra interferência na força de tensão e ou coeficiente de atrito do fio. Essa nova topografia reduz a superfície de contato dificultando assim fixação das bactérias e a formação do biofilme (Figura 3 e 4). O benefício é alcançado quando reduz a área de contato total para $30 \%$, com isso alcança-se lamelas menores que os próprios microrganismos, com 200-500 nm de espessuras e 
alguns micrometros de comprimento separadas entre 1-2 micrometros (SERRANO et al., 2015).
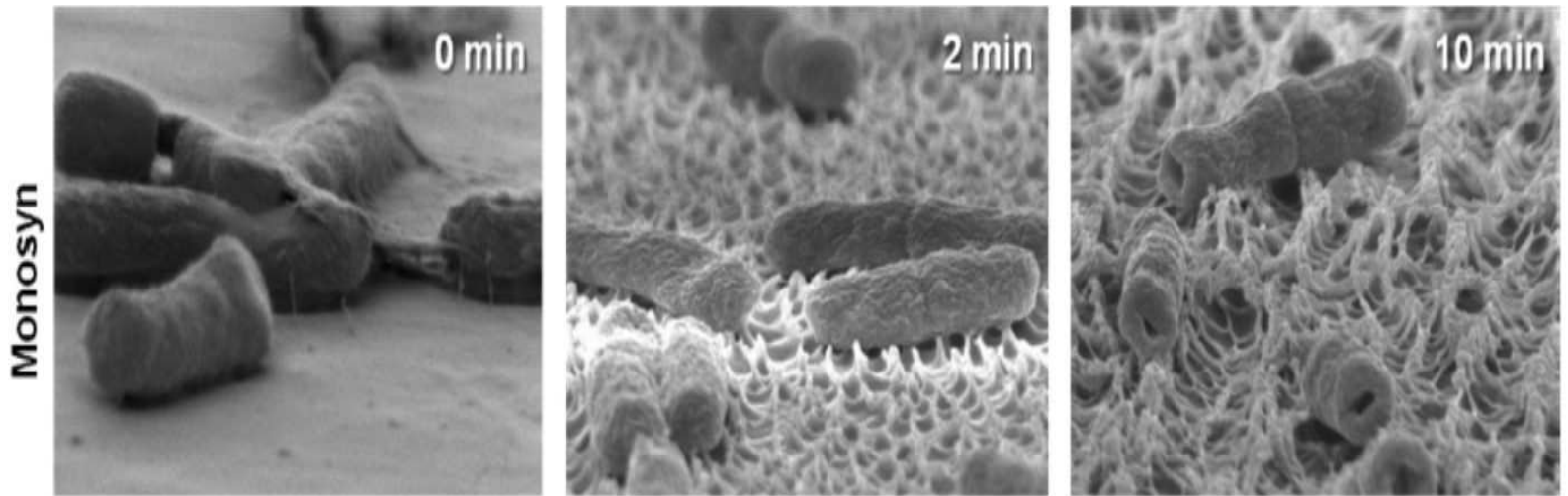

FIGURA 3- Fotomicrografia eletrônica mostrando a aderência de bactérias Escherichia coli ao fio de ácido poligliconato, Monosyn ${ }^{\circledR}$, antes e após dois e dez minutos de tratamento com plasma de oxigênio. Nota-se a redução da superfície de contato após o aumento do tempo exposição ao tratamento por plasma de oxigênio.

Fonte: SERRANO et al., (2015).

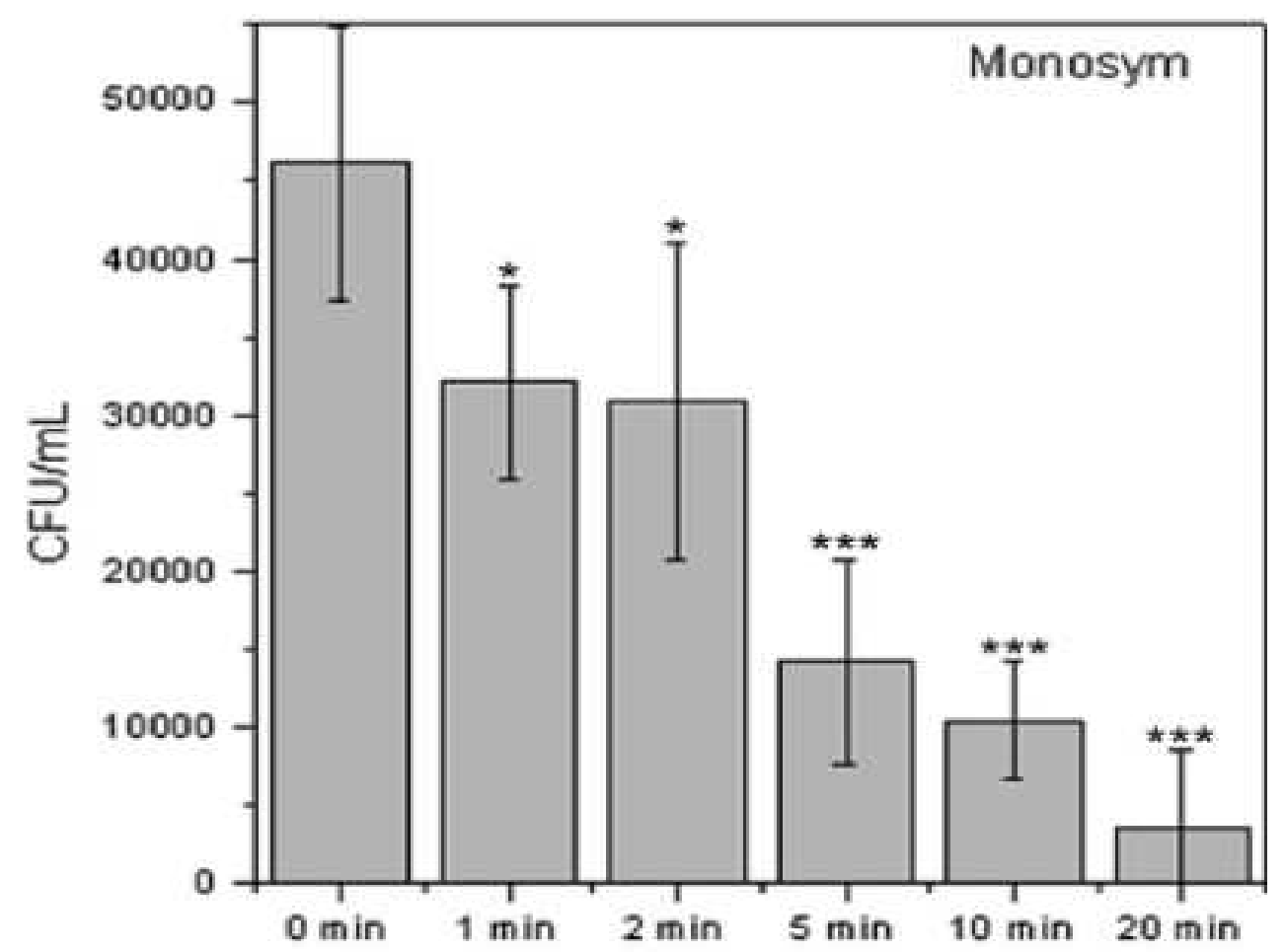

FIGURA 4- Redução da quantidade de unidades formadoras de colônia, de Echerichia. coli, no fio de ácido poligliconato Monosyn ${ }^{\circledR}$ após serem tratados com diferentes tempos de exposição ao plasma de oxigênio. As chaves em cima das barras representam o desvio padrão. CFU/mlUnidade Formadora de Colônia por ml. * $P<0,05 .{ }^{* *}-P$ $<0,01$. ${ }^{* * *}-\mathrm{P}<0,001$.

Fonte: SERRANO et al., (2015). 


\section{ESCOLHA DO FIO}

De forma geral o fio ideal deve ser atóxico, não alergênico, não carcinogênico, não trombogênico, atraumático, induzir baixa reação tecidual, ter boa pliabilidade, ser monofilamentar, resistente, flexível, porém não elástico, absorvível por hidrólise imediatamente após a recuperação da força tênsil natural do tecido e ter propriedades antimicrobianas. Acrescente-se que deve ser esterilizável, com boa estabilidade do nó ou ausência do mesmo, baixa capilaridade, baixa memória, de baixo custo, além de garantir uma força tênsil adequada para todos os tipos de tecidos até que este recupere parte suficiente da força de tensão natural. Alguns biomateriais empregados em suturas são disponibilizados para a utilização na Medicina Veterinária, sendo cada um com suas características peculiares. Mesmo com o advento da tecnologia, não se conseguiu associar todas as características em um mesmo biomaterial. Sendo assim, recomenda-se orientar a escolha do fio considerando alguns pilares, como o tipo de tecido, incluindo quantidade de tecido conjuntivo, órgão, características das feridas, incluindo tempo de cicatrização, recuperação da força tênsil natural (Figuras 5 e 6) e grau de inflamação e contaminação. Por último, mas, não menos importante, as características do material (GREENBERG \& CLARK, 2009).

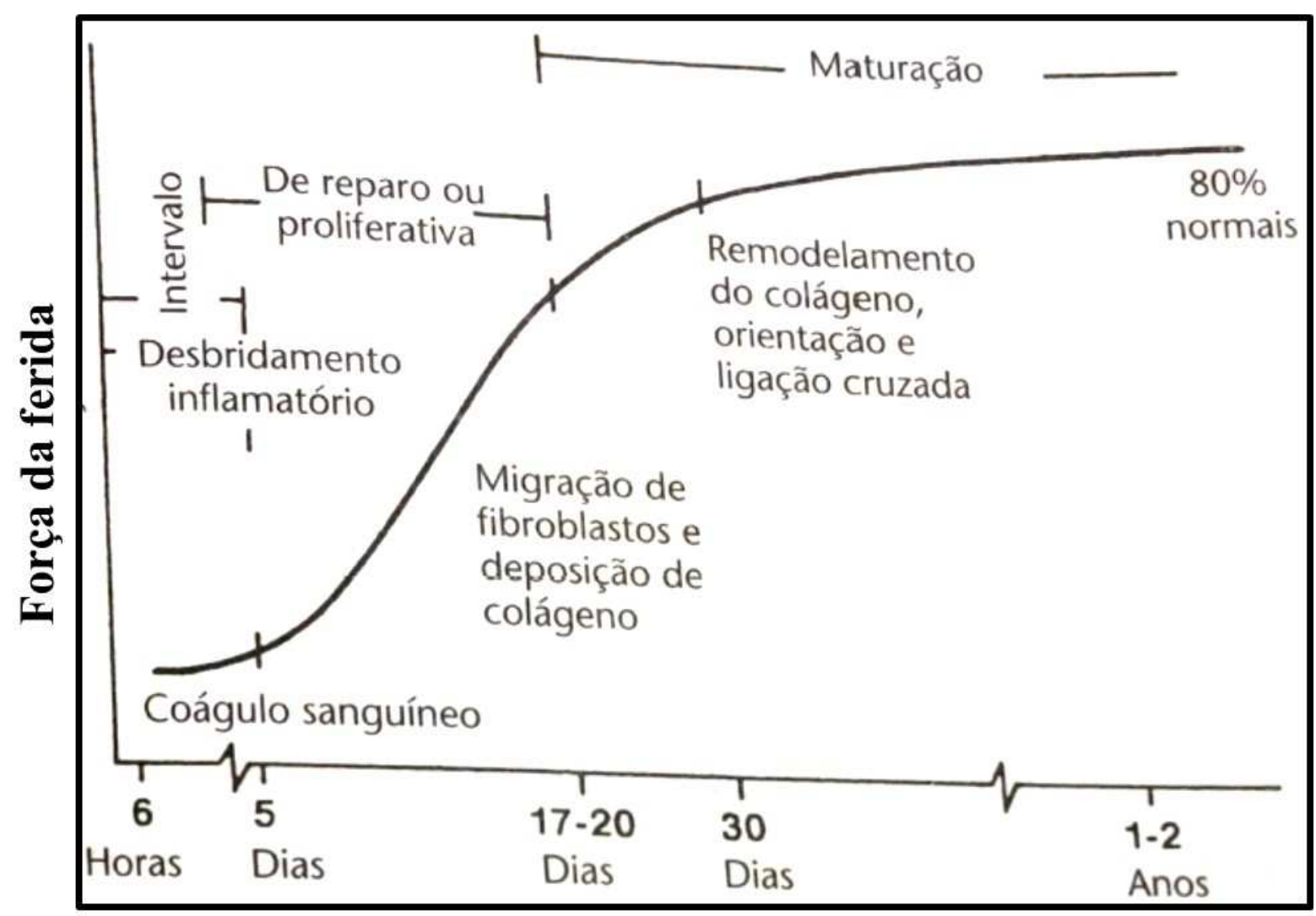

\section{Dias}

FIGURA 5- Alterações na força de ferida durante as etapas de cicatrização. Sendo mais acentuada no momento da fase proliferativa Fonte: HOSGOOD \& BURBA, (1998). 


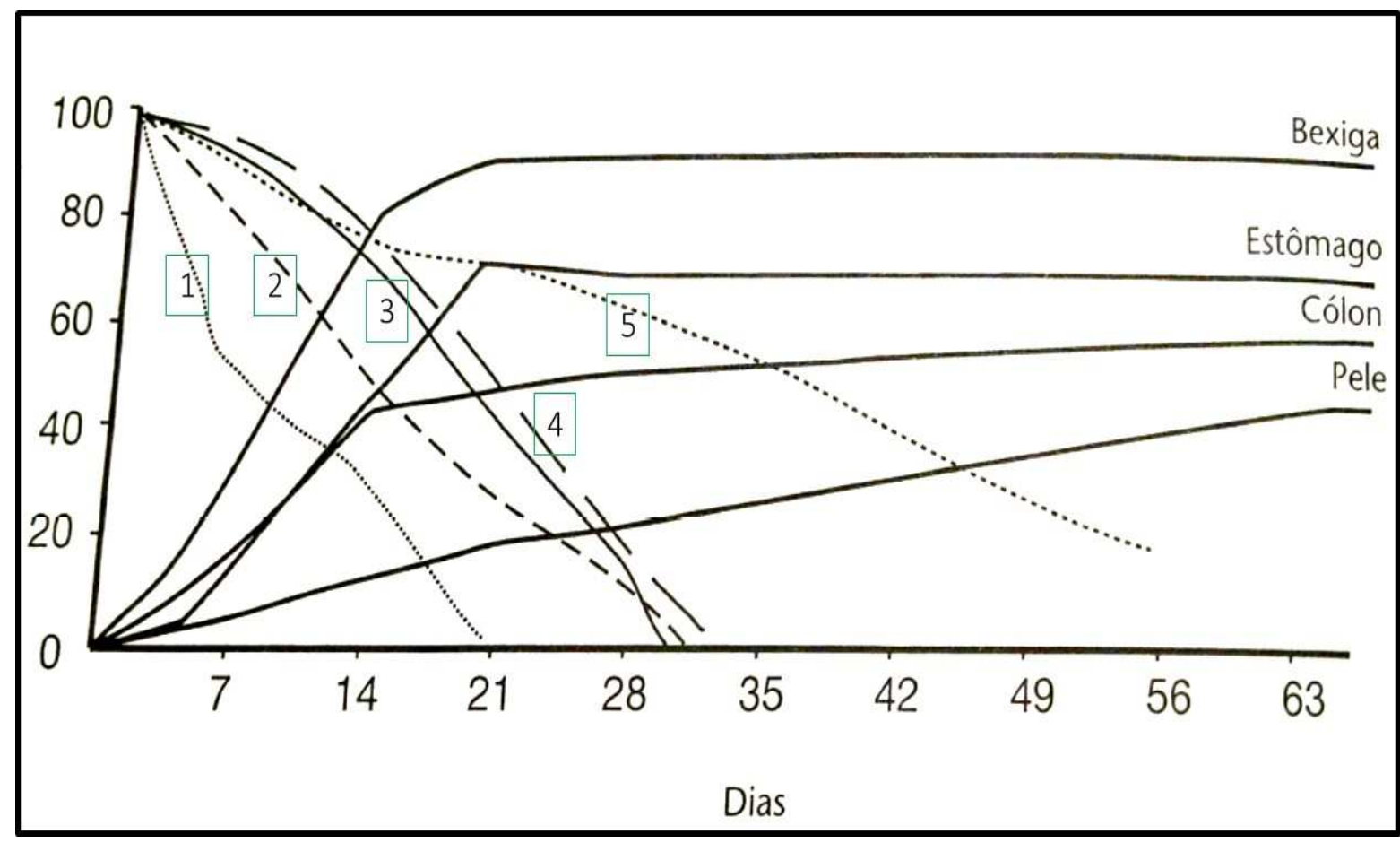

FIGURA 6- Relação entre perda de força tênsil dos fios de sutura absorvíveis selecionados e ganho em resistência de vários tecidos como resultado de cicatrização. 1- poliglecaprone 25. 2- categute cromado. 3- poliglicólico. 4- poliglactina. 5- Polidioxanona.

Fonte: adaptado de BOOTHE, (2007).

A espessura do fio deve ser a menor possível, mas suficiente para coaptar e estabilizar as bordas das feridas (Tabela 2). Sabe-se que quanto maior for a quantidade de material implantado maior é a quantidade de corpo estranho, consequentemente maior é a indução de reação tecidual. A região dos nós é a região com maior carga do biomaterial (GREENBERG \& GOLDMAN, 2013).

TABELA 2 - Diretrizes para a escolha do tamanho do fio de sutura, de acordo com cada sistema de medidas, em cirurgia de pequenos animais

\begin{tabular}{lcc}
\hline \multirow{2}{*}{ Tecido } & \multicolumn{2}{c}{ Tamanho do fio de sutura } \\
\cline { 2 - 3 } & USP & Métrico \\
\hline Pele & $4.0-2.0$ & $1,5-3,0$ \\
Subcutâneo & $4.0-3.0$ & $1,5-2,0$ \\
Fáscia & $3.0-0$ & $2,0-3,5$ \\
Músculo & $3.0-2.0$ & $2,0-3,0$ \\
Vísceras & $5.0-3.0$ & $1,0-2,0$ \\
Vasos & $4.0-1$ & $1,5-4,0$ \\
Tendão & $3.0-0$ & $2,0-3,5$ \\
\hline
\end{tabular}

Fonte: adaptado de BOOTHE, (2007). 


\section{CLASSIFICAÇÃO}

Os fios podem ser classificados de acordo com a origem (orgânica e sintética), absorção (absorvível ou inabsorvível) e quantidade de filamentos (mono e multifilamentares) (SILVERSTEIN \& KURTZMAN, 2005) (Figura 7). Quanto a origem, podem ainda ser divididos em animal (categute e seda), vegetal (algodão e linho) ou mineral (aço). Os fios multifilamentares podem ser torcidos (categute, algodão), trançados (seda, poliglactina, poliglicólico e poliamida) ou encapados em paralelo (aço). Nas últimas décadas desenvolveu-se, comercialmente, os fios farpados, circunstância que permite incluir uma nova classificação quanto a aparência do fio (liso ou farpado) (GREENBERG \& CLARK, 2009). Não se pode ignorar que as diversas características de um fio se correlacionam e influenciam à força de tensão, taxa de absorção, capacidade de manipulação, reatividade tecidual e segurança do nó (Quadro 1).
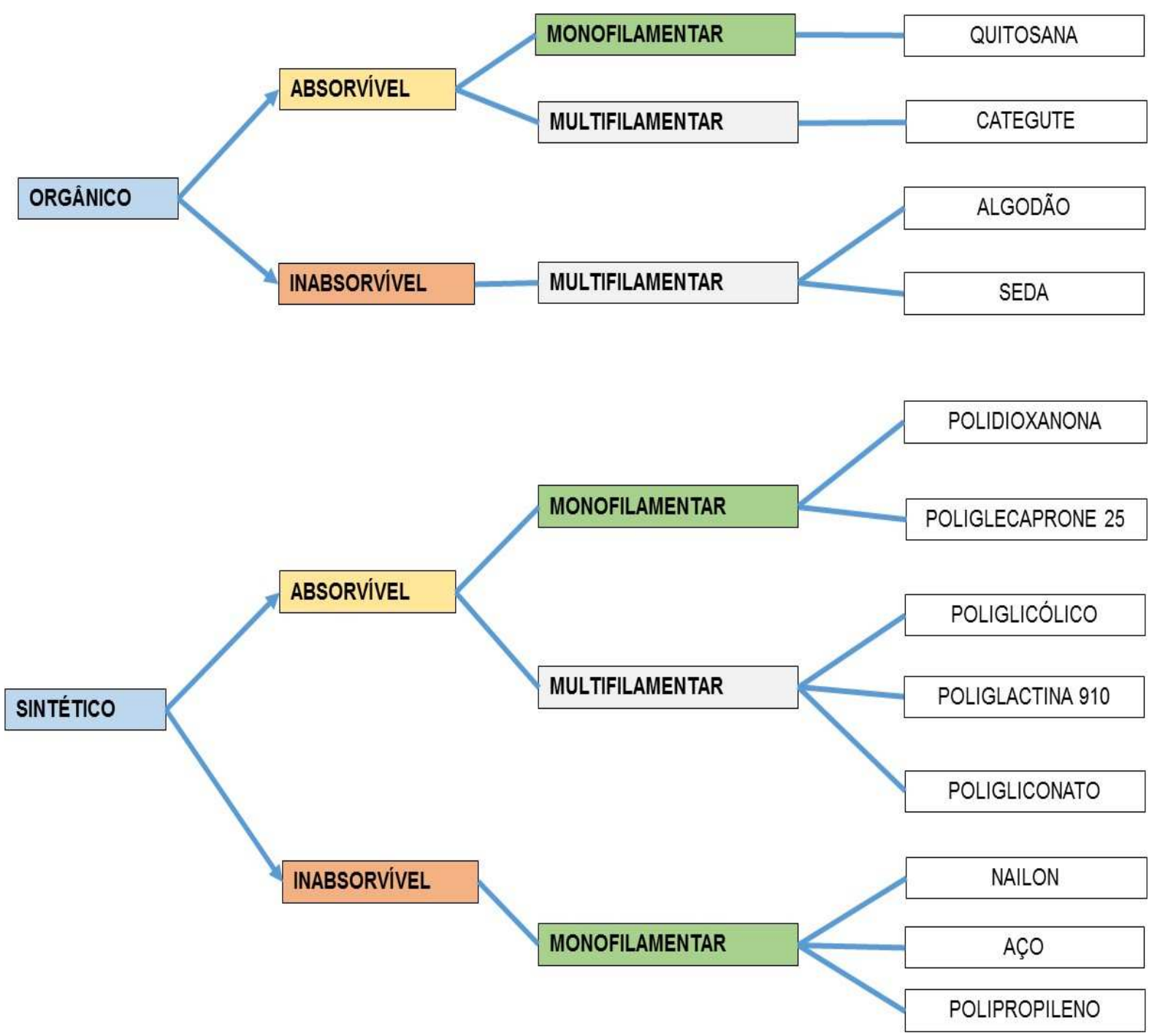

FIGURA 7- Classificações dos fios de sutura quanto a origem, absorção e quantidade de filamentos.

Os fios absorvíveis são aqueles que perdem a força tênsil, de maneira total, em até três meses (GREENBERG \& CLARK, 2009). De forma mais abrangente 
os fios absorvíveis não precisam ser removidos, porém observou-se em alguns casos que a permanência destes em contato com os tecidos, provocaram inflamação, granulação, fístula e abcessos, sanados apenas após a remoção (HOLZHEIMER, 2008). São indicados para sutura de tecidos viscerais, porém os mais resistentes como a polidioxanona e o poligliconato podem ser utilizados em tecidos de cicatrização lenta, como é o caso de fáscias e tendões (PEACOCK, 1984). Os sintéticos apresentam uma maior padronização da degradação da força tênsil, adicionalmente menor velocidade de absorção e menor indução de reação tecidual quando comparados aos de origem orgânica (GREENBERG \& CLARK, 2009).

QUADRO 1- Características, quantidade de filamentos, perda da força tênsil em 14 dias, absorção completa, força tênsil, qualidade de manipulação, reatividade e segurança dos nós de diferentes tipos de fios

\begin{tabular}{|l|c|c|c|c|c|c|c|}
\hline \multicolumn{1}{|c|}{ Nome } & Filamentos & $\begin{array}{c}\text { Perda } \\
\text { da } \\
\text { força } \\
\text { ao } \\
\mathbf{1 4} \\
\text { dia } \\
(\%)\end{array}$ & $\begin{array}{c}\text { Absorção } \\
\text { completa } \\
\text { (dias) }\end{array}$ & Força & Manuseio & $\begin{array}{c}\text { Reação } \\
\text { tecidual }\end{array}$ & Nó \\
\hline Categute & Multi & 50 & 60 & + & ++ & +++ & ++ \\
\hline Poliglícólico & Multi & 35 & 120 & ++ & +++ & + & + \\
\hline Poliglactina & Multi & 35 & 60 & +++ & +++ & + & + \\
\hline Poliglecaprone & Mono & 80 & 100 & +++ & ++++ & + & +++ \\
\hline Polidioxanona & Mono & 14 & 180 & ++++ & ++ & + & ++++ \\
\hline Náilon & Mono & $*$ & $*$ & ++ & ++ & ++ & + \\
\hline Polipropileno & Mono & $*$ & $*$ & ++ & ++ & + & + \\
\hline Aço & Mono & $*$ & $*$ & ++++ & + & + & ++++ \\
\hline Seda & Multi & 30 & $*$ & ++ & ++++ & +++ & +++ \\
\hline
\end{tabular}

Nomes coloridos em amarelo e vermelho correspondem respectivamente a fios absorvíveis e inabsorvíveis. ( $\left.{ }^{\star}\right)$ : não se aplica. Escala de + variando de 1-4

Fonte: adaptado de ROUSH, (2007).

Os fios inabsorvíveis garantem uma elevada força de tensão durante longos períodos de tempo. Por outro lado, podem causar dores crônicas, descarga vaginal e possuem maior chance de formar erosões durante o período pós operatório (JONES et al., 2009).

Os fios multifilamentares apresentam como desvantagens a indução de maior dano tecidual no momento da transfixação do tecido, maior fixação de bactérias, sendo de cinco a oito vezes maior do que no fio de náilon (monofilamentar) (KATZ et al.,1981), além de apresentar, na maioria das vezes, ENCICLOPÉDIA BIOSFERA, Centro Científico Conhecer - Goiânia, v.11 n.22; p. 330 
elevado potencial de capilaridade. Fatos que somados aumentam a indução de reação tecidual pelo trauma e pela disseminação de microrganismos ao longo dos planos da ferida (CHU et al., 1996). Em contrapartida, são mais maleáveis e de melhor pliabilidade quando comparados aos monofilamentares (RODEHEAVER, 1987). Estes por sua vez resistem mais a infecção e geralmente apresentam melhor comportamento quando empregados em ambientes contaminados, além de que quando absorvíveis possuem taxa de absorção mais lenta. Por outro lado, possuem maior insegurança do nó, sendo recomendado aplicação de nós adicionais (GALLUP, 2001).

\section{ABSORVÍVEIS MULTIFILAMENTARES}

\section{Categute}

O categute é um fio orgânico de origem animal, produzido da submucosa do intestino de ovinos ou da serosa intestinal dos bovinos, constituído de colágeno e tratados com formaldeído. É torcido e esterilizado por ação do óxido de etileno, fato que aumenta o tempo de absorção (GREENBERG \& CLARK, 2009). Também podese empregar na esterilização a radiação ionizante. Não deve ser autoclavado, pois altas temperaturas desnaturam as proteínas do colágeno, influenciando na perda de resistência do fio (POLK, 2001). São encontrados comercialmente, nas formas simples e cromada com os nomes Catgut ${ }^{\circledR}$, Biogut ${ }^{\circledR}$, Tech-gut ${ }^{\circledR}$. O banho com sais de cromo aumenta a resistência à tensão, diminui a indução de reação tecidual e retarda a absorção (GREENBERG \& CLARK, 2009). A absorção completa pode ser prolongada, porém o categute cromado apresenta perda de $33 \%$ da força tênsil em sete dias e 67\% após 28 dias (POLK, 2001). Já o categute simples é absorvido entre cinco e sete dias. Esse processo é feito por um mecanismo duplo. Inicialmente ocorre a quebra das ligações por ação do ácido hidrolítico e atividade das colagenases. No segundo momento, ocorre a digestão e absorção por ação das enzimas proteolíticas lisossomais dos neutrófilos e macrófagos (BELLENGER, 1982).

A constituição à base de colágeno propicia o reconhecimento de proteína heteróloga ou xenóloga pelo receptor do biomaterial, iniciando assim uma reação de corpo estranho no leito receptor. A composição também propicia redução da força tênsil e, consequentemente, aumento na taxa de absorção, quando implantados em animais caquéticos (catabolismo acentuado), em órgãos como intestino e estômago (rico em enzimas proteolíticas), ou ainda quando utilizados para síntese de feridas altamente vascularizadas e ou infectadas. O fato de ser torcido cria vários pontos de fragilidade no fio e possibilita o esgarçamento (GREENBERG \& CLARK, 2009).

De forma geral o categute, apresenta várias desvantagens, dentre elas destaca-se a indução de uma grande reação tecidual, falta de segurança do nó, principalmente quando molhado, apresenta capilaridade, inconstante taxa da perda de força tênsil e há relatos de reação de sensibilidade em animais, sendo mais pronunciada nos felinos domésticos (HERMANN, 1971). Outra desvantagem é a indução da formação de aderência (Figura 8). Tal desvantagem foi relatada em um estudo que observou a reparação da miorrafia, do corno uterino, por cirurgia laparoscópica em ovinos. Neste, notou-se formação de aderências em $71,4 \%$ dos sete ovinos que representava o total da amostragem do experimento. Sendo que $80 \%$ dessas aderências ocorreram entre vísceras e apenas $20 \%$ entre o corno 
uterino e o omento (HUAIXAN, 2013). A utilização do categute simples é raramente indicada (BELLENGER, 1982). É limitado a ligadura de vasos sanguíneos do tecido subcutâneo e é frequentemente utilizado em procedimentos orais (GLICKMAN \& HARTEWELL, 2008).

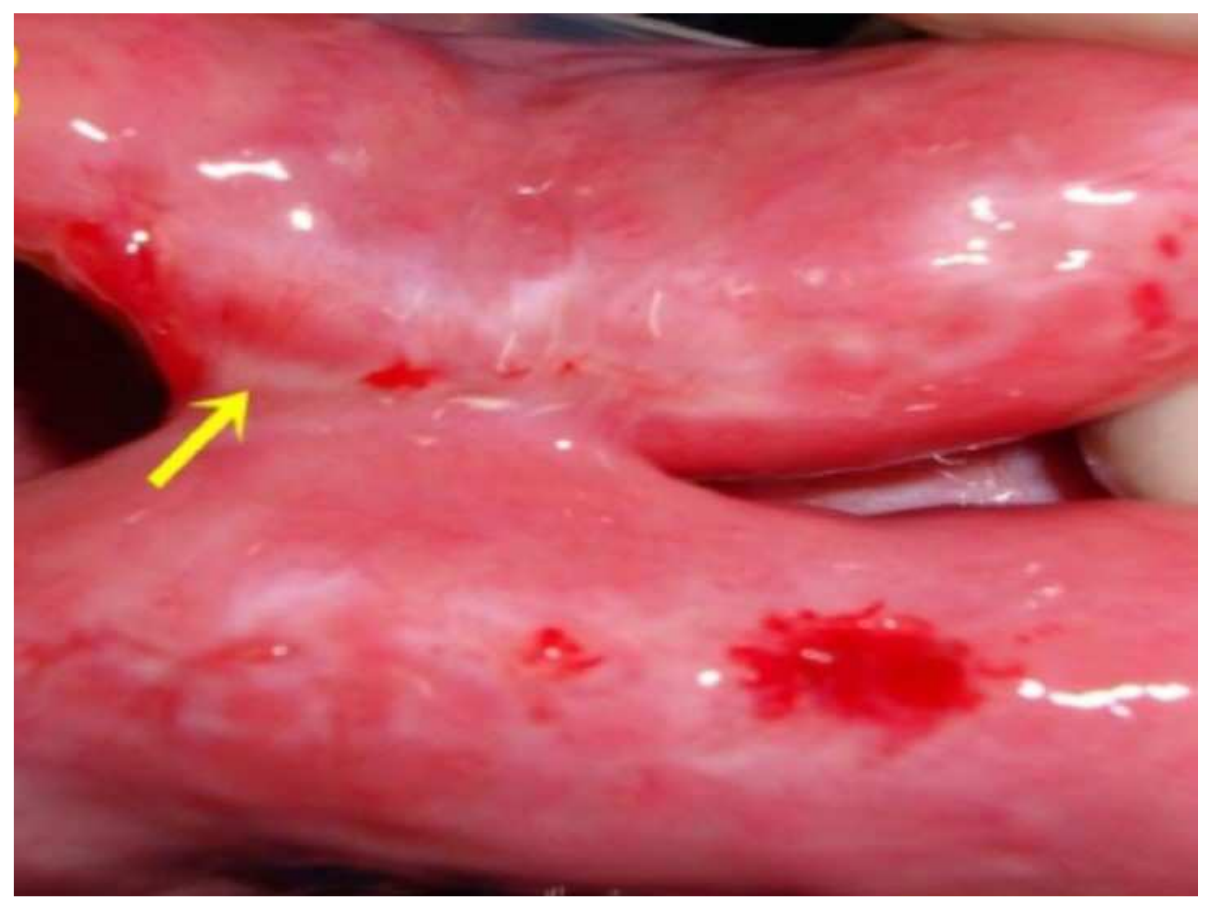

FIGURA 8- Imagem laparoscópica, indicando a presença de aderência (seta) da área de rafia com categute entre os cornos uterino de um ovino, após 30 dias do procedimento.

Fonte: HUAIXAN, (2013).

\section{Ácido poliglicólico}

E um fio sintético, composto por polímeros trançados do ácido glicólico (hidroxiacético). É bastante resistente e induz discreta reação tecidual, sendo comparado à outros fios sintéticos como o náilon e a poliglactina 910. Ocorre perda de $33 \%$ da força tênsil até sete dias e cerca de $80 \%$ até 14 dias, tendo absorção completa estimada em 120 dias (POSTLETHWAIT, 1970). Entretanto, foi totalmente absorvido em sete dias quando aplicada na cavidade oral (KAKOE et al., 2010). A absorção ocorre por hidrólise, sendo acelerada em ambientes alcalinos (BELLENGER, 1982). Deve ser utilizado com cautela em cistotomias de pacientes com cistite com elevação do pH urinário, pois além de acelerar a absorção, reduz a força de tensão (SMEAK \& WENDELBURG 1989).

Adicionalmente, em outro estudo, concluíram que a utilização deste fio, promoveu a calcificação da linha de sutura em $66,67 \%$ das feridas de 24 cadelas com urina ácida após o vigésimo primeiro dia do procedimento de iliocistoplastia, fato que pode predispor a formação de urólitos (FERREIRA et al., 2005). Devido ao fato de ser multifilamentar, provoca notável atrito ao transpassar os tecidos, facilitando à ruptura de tecidos friáveis, fato que pode ser minimizado umedecendo o fio antes do uso. O nó possui baixa segurança (BELLENGER, 1982). Apesar de ter uma superfície bastante aderente, pode ser utilizado em ambientes infectados, uma 
vez que estudos "in vitro" demonstraram que a liberação de ácido glicólico proveniente da degradação do fio apresentou potencial antibacteriano. Também é indicado para aproximação do tecido subcutâneo (SMEAK \& WENDELBURG 1989). Comercialmente os fios são denominados Dexon ${ }^{\circledR}$ e Safil ${ }^{\circledR}$.

\section{Poliglactina 910}

É um fio sintético, formado pela associação com 90\% ácido glicólico e $10 \%$ de ácido lático, absorvido por hidrólise. Por conter molécula mais hidrofóbica, quando comparado ao ácido poliglicólico, é mais resistente à absorção, notando-se maior força de tensão até 21 dias após implantação. Provoca mínimas reações teciduais, é de fácil manuseio e é estável mesmo em feridas contaminadas (CRAIG, 1975). É encontrado comercialmente com o nome Vicryl ${ }^{\circledR}$. Apresenta grande resistência frente a urina alcalina, podendo ser utilizado com segurança em cistotomias (FREEMAN, 1987), sendo que quando aplicado neste órgão propiciou a recuperação total da força tênsil natural em 14 a 21 dias (ELLISON, 1996). Indica-se o uso também em diversos procedimentos de suturas sepultadas, sendo considerado ideal para o reparo de feridas de episiotomia ou de cirurgia perineal como um todo (GREENBERG \& CLARK, 2009). A utilização também foi avaliada e comparada com o ácido poliglicólico em reparação de iliocistoplastia em 24 cadelas. Neste observaram que o fio de poliglactina foi mais indicado uma vez que apresentou sinal de reparação mais precoce (sétimo dia vs 21 dias), processo inflamatório mais discreto e ausência de supuração e calcificação, observados no outro grupo (FERREIRA et al., 2005).

Em um estudo propuseram a comparação do fio poliglactina com 0 categute cromado. Para tanto, utilizaram 200 mulheres em cada grupo, as quais foram submetidas a episiotomia durante o parto. Foi observado após três a cinco dias de pós-operatório maior frequência de mulheres com ausência de dor $(57 \%$ vs $32,5 \%)$, menor formação de edema ( $7 \%$ vs $13,5 \%)$ ausência de secreção $(0 \%$ vs $3,5 \%)$, menor desconforto relacionado a presença dos pontos (12,5\% vs $27 \%$ ) e menor ocorrência de deiscência da ferida (Figura 9). Em uma avaliação adicional após seis semanas, observaram menor incidência de deiscência de feridas $(3,5 \% \mathrm{vs}$ $13,5 \%$ ), de infecção (0 \% vs 4\%) e, finalmente, menor índice de reintervenções ( $0 \%$ vs $2 \%$ ) quando comparado com o categute cromado (BHARATHI et al., 2013).

\section{ABSORVÍVEIS MONOFILAMENTARES}

\section{Poliglecaprone 25}

Poliglecaprone 25 (Monocryl $^{\circledR}$, Caprofyl $^{\circledR}$ ) é sintético, altamente flexível, composto por $75 \%$ de glicolida e $25 \%$ de coprolactona. Tem uma excelente força tênsil inicial, porém apresenta rápida degradação. É mantida em 40-50\% na primeira semana e $20-30 \%$ na segunda, sendo inexistente após a terceira semana. A absorção total ocorre de maneira rápida e por hidrólise em 91-119 dias, produzindo discreta reação tecidual, a qual mesmo comparada com as respostas obtidas pelos fios de poliglactina e ácido poliglicólico, mostrou-se superior na qualidade (BOOTHE, 1998). É recomendado com cautela para uso em sutura da musculatura abdominal (BELLENGER, 1982; MOLEA et al., 2000) e sem restrições para ligaduras e rafias 
de tecidos moles em geral, incluindo o intestino, cirurgias urológicas, reparação muscular, histerorafia pós cesariana e redução do tecido subcutâneo (BEZWADA et al., 1995; KIRPENSTEIJN et al., 2001 GREENBERG \& CLARK, 2009).

$O$ fio de poliglecaprone foi analisado em 24 gatas submetidas à ovariosalpingohisterectomia (OSH), para ligadura do pedículo ovariano, coto uterino e fechamento da musculatura abdominal, sendo efetivamente condizente com a cicatrização de todos os planos. Não houve deiscência de ferida e consequentes herniação em nenhum animal. Igualmente observado com outros fios, quando se trata de felinos (FREEMAN, 1987), ocorreu seroma no tecido subcutâneo, porém com reabsorção total até o vigésimo oitavo dia de pós-operatório (RUNK et al.,1999). Resultados satisfatórios foram relatados, em outro estudo, quando se comparou o fio de poliglecaprone ao polipropileno, na reparação de cecotomia em 72 ratos. Observaram ausência de abcesso ou peritonite e boa resistência à insuflação após o sétimo dia. Microscopicamente notou-se que após o décimo quarto dia foi evidenciada reação inflamatória discreta e aumento importante da proliferação fibroblástica e deposição de colágeno, o que caracterizou uma boa condução do processo de cicatrização (NOMURA et al., 2009).

O poliglecaprone também foi comparado à poliglactina 910 quando aplicados a sutura extramucosa do estômago em 14 cães. Esses apresentaram reação inflamatória discreta, porém o fio de poliglecaprone foi considerado superior devido às vantagens de manipulação, como o menor coeficiente de atrito (SANTOS FILHO, 2004). Além desses, quando avaliado na musculatura glútea de ratos e observados entre três e 91 dias de pós-operatório, foram notadas reações histológicas discretas, com presença de macrófagos e fibroblasto, poucos linfócitos, plasmócitos, netrófilos e ocasionais células gigantes (BEZWADA et al., 1995).

\section{Polidioxanona}

É um fio sintético, de alto custo, encontrado no mercado com o nome $\mathrm{PDS}^{\circledR}$. É produzido pelo polímero de paradioxanona com flexibilidade superior aos fios de poliglicólico, poliglactina 910 e polipropileno. Tem grande resistência (Tabela 3 ), sendo maior que a do náilon e polipropileno quando testada antes da implantação. A absorção ocorre lentamente por hidrólise ao longo de 182 dias. Perde $26 \%$ da força tênsil após 14 dias, $42 \%$ após 28 dias e $86 \%$ depois de 56 dias (RAY, 1981). Entretanto, foi relatado que apesar de alterações microscópicas estruturais, a força tênsil não foi alterada de maneira significativa, durante os primeiros 35 dias de avaliação, mesmo sendo implantada em locais diferentes de coelhos, tais como sobre a fáscia do músculo reto abdominal, sobre o peritônio ou "in vitro" em solução de ringer com lactato (METZ, 1990). 
TABELA 3- Força média e seus respectivos desvio padrão, medida por um tensiômetro com velocidade de $5 \mathrm{~mm} /$ minuto, necessária para promover a ruptura do nó em variados fios absorvíveis de espessura USP 2.0, após 60 minutos de imersão em solução salina a 0,9\%

\begin{tabular}{lccc}
\hline Material & $\begin{array}{c}\text { Quantidade de } \\
\text { testes (unidade) }\end{array}$ & Média (Newtons) & Desvio padrão \\
\hline Poliglactina & 32 & 81.1 & 28.1 \\
Seda & 6 & 58.7 & 2.7 \\
Polidioxanona & 5 & 109,1 & 8,1 \\
Categute cromado & 5 & 66,9 & 3,9 \\
Total & 48 & 79,7 & 26,3 \\
\hline
\end{tabular}

Fonte: adaptado de MUFFLY et al., (2010).

Sendo assim, é recomendado para a sutura de fáscias, incluído a bainha externa do músculo reto abdominal (GREENBERG \& CLARK, 2009), e de tendões (WALTON, 1989). Recomendado também em tecidos infectados e pancreático (LACERDA, 2013). Existe experiência relatada em procedimento com fixação de telas, uma vez que a incorporação do tecido ao material é o passo limitante para adequada fixação (IMPARATO et al., 1992). Induz reação tecidual pequena, similar aos outros fios absorvíveis sintéticos. Possui pequena memória e apresenta boa segurança do nó (ROSIN \& ROBINSON, 1989).

\section{Quitosana}

A quitosana é um homopolissacarídeo estrutural, o que garante menor indução de reação tecidual quando comparado aos fios de origem protéica, como a seda (fibroina) (CHU et al., 1996). Provém da desacetilação da quitina, que é extraída de fungos, do exoesqueleto de insetos e, principalmente, de crustáceos incluindo lagosta, camarão e caranguejo. É o segundo biomaterial mais disponível, atrás apenas da celulose (ROSA, 2008). Os fios provenientes desse material têm característica de ser absorvíveis por hidrólise, principalmente em meio ácido (Quadro 2), indutor de discreta resposta tecidual, bacteriostático, atóxico, biocompatível e monofilamentar (MONTENEGRO \& GODEIRO, 2014).

QUADRO 2- Tempo versus pH para a completa dissolução (+) da sutura QiGel ${ }^{\circledR}$

\begin{tabular}{|l|c|c|c|c|c|}
\hline \multicolumn{7}{|c|}{ Tempo } \\
\hline pH & $1 \mathrm{~h}$ & $2 \mathrm{~h}$ & $\mathbf{3 h}$ & $\mathbf{4 h}$ & $5 \mathrm{~h}$ \\
\hline 5.5 & - & - & - & - & + \\
\hline 5.0 & - & - & + & + & + \\
\hline
\end{tabular}

Fonte: MONTENEGRO \& GODEIRO, (2014).

O fio cirúrgico produzido com quitosana foi testado em apenas dois estudos "in vivo". Uma das pesquisas avaliou o fio em relação a cicatrização após 30 dias do procedimento de histerorrafia laparoscópica em sete ovinos. Os resultados mostraram-se promissores, uma vez que resultou em discreta reação tecidual, com 
menor presença de linfócitos, e promoveu menos aderência quando comparado ao fio de categute. Observou-se também maior deposição de colágeno tipo III (Figura 9), fato que corroborou com uma melhor cicatrização. Além dessas características, o fio de quitosana garantiu tensão das bordas da ferida até a cicatrização do útero (HUAIXAN, 2013).

Em outro estudo, sobre o fio de quitosana empregado na musculatura abdominal de ratos foi observada menor reação tecidual, considerando a quantidade de macrófagos, quando comparado com fio de náilon, tendo potencial de gerar menor formação de cicatrizes. Possui efeito bacteriostático no mínimo duas vezes mais duradouro, quando comparado a outros fios com incorporação de antibióticos disponíveis no mercado, principalmente quando em meio com fluidos. Apesar de apresentar resultados promissores, o $\mathrm{QiGe}^{\circledR}$, nome comercial, ainda é pouco divulgado no meio científico e pouco difundido comercialmente (MONTENEGRO \& GODEIRO, 2014).

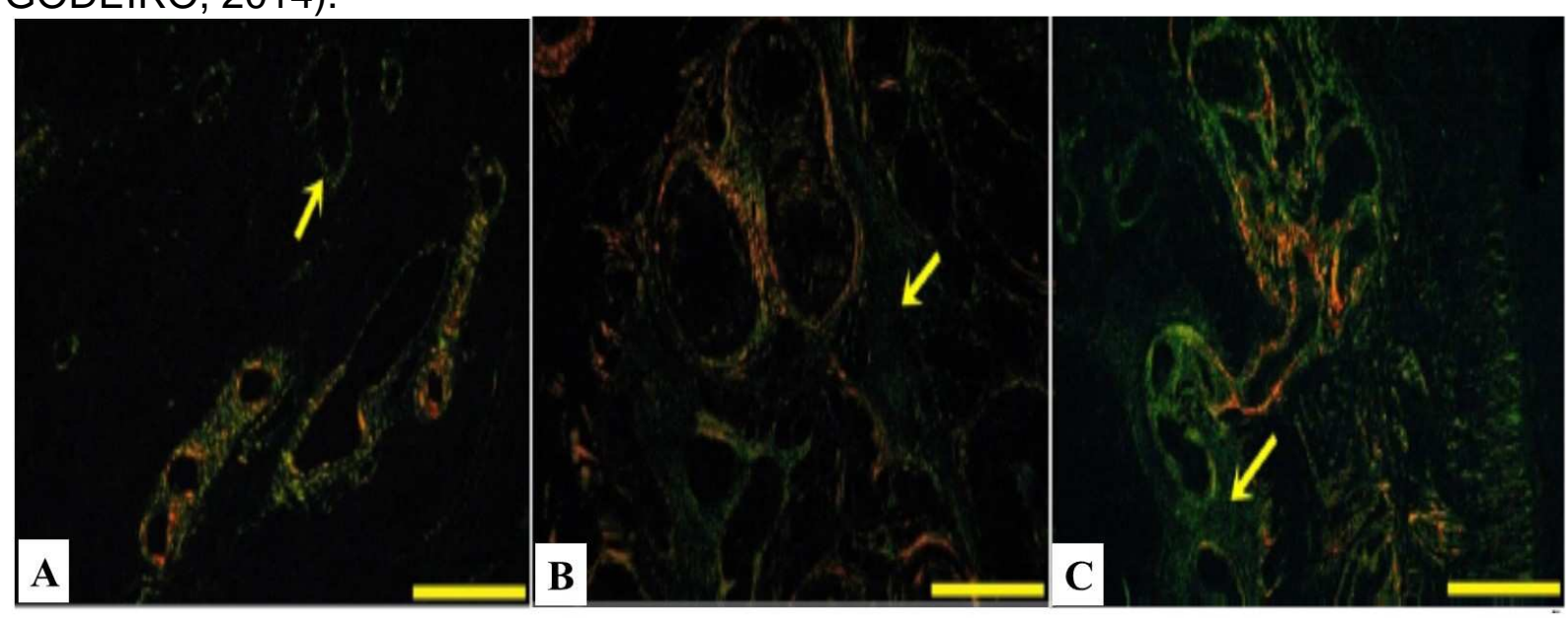

FIGURA 9- Fotomicrografia (Picrossirius red) mostrando a disposição dos colágenos do tipo III (seta) em útero de ovelhas após 30 dias de miorrafia. Observa-se maior proporção em C. (A) - área não lesada. (B) - miorrafia com categute. (C)- miorrafia com quitosana. Escala: $60 \mu \mathrm{m}$.

Fonte: adaptado de HUAIXAN, (2013).

\section{INABSORVÍVEIS MULTIFILAMENTARES}

São representados principalmente pelos fios de seda, algodão e linho. Estão sendo cada vez menos utilizados devido à expressiva indução de reação tecidual, e grande capilaridade (GREENBERG \& CLARK, 2009). A utilização é então, na maioria das vezes, justificada pelo baixo custo e principalmente aplicada aos animais de produção ou em campanhas de esterilização de pequenos animais.

\section{Seda}

Fio de origem orgânica (animal), obtido do casulo do bicho-da-seda, pode ser encontrado na forma torcido ou trançado, com os nomes Seda ${ }^{\circledR}$ ou Tech-lin ${ }^{\circledR}$. Possui alta capilaridade a qual pode ser amenizada por imersão em solução de óleo, cera ou silicone. Tem perda gradual da força de tensão e pode ser completamente absorvido após dois anos (STASHAK \& YTURRASPE, 1978). A principal vantagem ENCICLOPÉDIA BIOSFERA, Centro Científico Conhecer - Goiânia, v.11 n.22; p. 336 2015 
se limita ao preço extremamente reduzido (SILVERSTEIN \& KURTZMAN, 2005) e a ótima pliabilidade, sendo considerada por muitos como o fio de melhor manipulação (RATNER et al., 2004). Por outro lado, as desvantagens são inúmeras, dentre elas a menor força tênsil entre os tipos de fio, falta de segurança no nó, potencializada quando o fio sofre tratamento por imersão (GREENWALD et al., 1994); indução de severa reação tecidual quando comparada a outros fios de sutura inabsorvíveis; alta susceptibilidade a invasão bacteriana e retardo do processo de cicatrização (VASTARDIS \& YUKNA, 2003).

Resultados de exames histológicos da implantação de fios no tecido oral mostraram a maior presença de neutrófilos (ABI RACHEDED et al., 1992) e menor precocidade no aparecimento de neovasos e dos fibroblastos quando utilizados fios de seda comparado ao náilon, poliglecaprone 25, poliglactina e ácido poliglicólico (JAVED et al., 2010). Adicionalmente, comparado ao categute simples, também apresentou maior inflamação, caracterizada pela predominante presença de macrófagos e neutrófilos e menor precocidade na formação do tecido conjuntivo ao quarto dia pós-operatório (KAKOEl et al., 2010). Apesar disto, ainda é um material frequentemente utilizado pelos dentistas (MCDONALD \& TORABINEJAD, 2002). Deve-se evitar uso em feridas contaminadas, pois a superfície bastante aderente e seus interstícios permitem a fixação de sangue e fluidos inflamatórios, criando ambiente propício para a proliferação bacteriana. Não é recomendado na vesícula biliar e urinária, pois existe o risco de formação de cálculos. Além do mais, apresenta grande potencial para produzir ulceração intestinal, quando o fio atingir o lúmen desses órgãos (SWAIM, 1980).

\section{Algodão}

Fio de origem orgânica (vegetal), que perde lentamente a força tênsil com decaimento de $50 \%$ em seis meses e $70 \%$ em dois anos, porém diferentemente da seda não é absorvido completamente (SRUGI \& ADAMSON, 1972). Disponível comercialmente com os nomes Algodão ${ }^{\circledR}$ e Tech-cott ${ }^{\circledR}$. A vantagem limita-se ao baixo custo e possibilidade de ser autoclavado. Quando molhado tem a resistência aumentada em 10\% e alta segurança do nó (STASHAK \& YTURRASPE, 1978). Por outro lado, a reação tecidual é intensa igualmente a da seda, apresenta alta capilaridade e manipulação prejudicada devido ao potencial eletrostático (BELLENGER, 1982).

Algumas das desvantagens foram, também, observadas em experimentos com sutura de pele, na região cervical, em oito equinos com posterior avaliação aos cinco e dez dias de cicatrização. Neste, o fio de algodão provocou formação de maior edema subcutâneo e induziu maior exsudação da ferida quando comparado com coprolactona, polipropileno e náilon. A reação tecidual microscópica também foi avaliada e assim como os outros resultados, o grupo do algodão diferiu estatisticamente dos outros apresentando maior proporção das lesões com inflamação leucocitária grave e difusa ao invés de moderada e perivascular (MALDONATO et al., 2006).

Em pequenos animais, observa-se principalmente a utilização do fio de algodão em campanhas de esterilização ou por cirurgiões mais antigos, devido respectivamente à redução de custos ou à grande segurança do nó nas ligaduras dos pedículos ovarianos. Entretanto, observa-se em vários relatos de caso, seja com maior ou menor intervalo de tempo pós-operatório, complicações como formação de 
fístulas, granulomas, aderências e hidronefrose decorrentes dessa prática. Sendo essas atribuídas, principalmente, à reação tecidual exacerbada induzida pela presença de corpo estranho (SANTOS et al., 2009; NASCIMENTO et al., 2012; ATALLAH et al., 2013). Também foram notadas algumas desvantagens quando empregado na sutura extramucosa das enteroanastomes em 20 cães. Neste observou-se, durante o período pós operatório de 21 dias, maior aderência com o omento e entre alças e presença de inflamação granulomatosa, caracterizada por macrófagos e células epiteliódes gigantes, mais severa quando comparado aos fios poliglecaprone 25 e poliglactina 910 (BERNIS FILHO et al.,2013).

\section{INABSORVIVEIS MONOFILAMENTARES}

\section{Aço}

O aço inoxidável é o único fio metálico atualmente utilizado. É inerte e pode ser esterilizado facilmente por autoclave. Pode ser encontrado na forma mono ou multifilamentar torcido, com os nomes Aciflex $^{\circledR}$ ou Monicron ${ }^{\circledR}$. Possui extrema força de tensão, a qual não sofre redução e maior segurança de nó entre todos os tipos de fio (STASHAK \& YTURRASPE, 1978). Não induz resposta inflamatória, a menos que ocorra instabilidade da ferida e atrito da mesma com o fio (SWAIM, 1980). Tem o uso indicado, em tecido com cicatrização demorada, como nos casos de cerclagem ósseas. No fechamento de toracotomias por esternotomia mediana prefere-se este a fios monofilamentares sintéticos, pois garantem melhor estabilização, cura mais rápida e menos dor no pós-operatório (PELSUE, 1999).

Entretanto, como desvantagens apresentam tendência de cortar os tecidos, é de difícil manuseio e apresenta grande chance de fraturar em casos de manejo excessivo. Nesses casos pode ocorrer a migração do biomaterial (SRUGI \& ADAMSON, 1972). Outra causa de migração se dá pela atração do fio ferromagnético durante exames de ressonância magnética, procedimento esse que deve ser evitado.

\section{Náilon}

É um fio sintético derivado das poliamidas, mais precisamente do ácido hexametilenodiamina e ácido adípico (BELLENGER, 1982). Possui força de tensão moderada, sendo similar ao polipropileno (HERMANN, 1971). Reduz apenas $30 \%$ da força tênsil em aproximadamente dois anos, devido a degradação química (STASHAK \& YTURRASPE, 1978). Como vantagens apresenta baixa indução de reação tecidual e induz menor incidência de infecção em tecidos contaminados. Essa vantagem é imputada também ao polipropileno quando comparados a outros fios inabsorvíveis (SHARP, 1982). Como principal indicação tem-se as dermorrafias, incluindo blefaroplastia (AHN et al., 2011) e a sutura de nervos periféricos (BELLENGER, 1982). Observaram após 27 dermorrafias em vacas, um excelente escore de ferida. Tal escore caracterizava-se por mínima inflamação, ausência de secreção, infecção ou deiscência da ferida (ISLAM et al., 2014). Em outro estudo, observaram exsudação de ferida cutânea cervical em equinos. A avaliação no quinto dia pós-operatório confirmou que o fio de náilon foi o único, dentre polipropileno, algodão e coprolactona que não apresentou essa complicação (MALDONATO et al., 2006). 
Deve-se evitar o uso em órgãos tubulares, pois as pontas sepultadas podem causar irritação por atrito (BELLENGER, 1982). Não devem utilizá-lo em cistotomias, da mesma maneira que outros fios inabsorvíveis. A exposição prologada do material de sutura ao lúmen do trato urinário pode agir como corpo estranho, servindo como núcleo para a formação de cálculos (MCLOUGHLIN, 2011). Como desvantagens apresenta alta memória, dificuldade de manuseio, além de ser considerado, "in vitro", o fio com menor segurança no nó, fato controlado por aplicação de no mínimo cinco semi-nós (STASHAK \& YTURRASPE, 1978). Possui grande distribuição no mercado, sendo principalmente encontrado com os nomes Nylon ${ }^{\circledR}$, Mononylon ${ }^{\circledR}$, Superlon ${ }^{\circledR}$, Dermalon ${ }^{\circledR}$, Dafilon ${ }^{\circledR}$.

\section{Polipropileno}

É um fio sintético, inerte, formado por um polímero de polipropileno, derivado do gás propano. Conhecido comercialmente por Prolene ${ }^{\circledR}$, Propilene ${ }^{\circledR}$, Supralene ${ }^{\circledR}$ e Premilene ${ }^{\circledR}$. Pode ser esterilizado pela ação do óxido de etileno (HOLT \& HOLT, 1981). Apresenta moderada segurança ao nó, porém alta quando comparada a outros fios monofilamentares, com exceção do fio de aço (SWAIM, 1980). Como vantagens destacam-se: a baixa trombogenicidade (HOLT \& HOLT, 1981), baixo arrasto tecidual, ínfima indução de reação tecidual e a manutenção da força de tensão, além de possuir boa flexibilidade (PAPAZOGLOU et a., 2010). Fatos que conferem potencial para a utilização em miorrafia, dermorrafia, sistema nervoso periférico (BELLENGER, 1982), e principalmente no sistema cardiovascular como um todo (CHU, 1981).

Foi testado e com ótimos resultados clínicos e microscópicos em suturas intradérmicas em cães que apresentavam feridas com tensão significativa. Notaramse a prevenção da formação de cicatrizes (SWAIM, 1980). Em outra pesquisa, foi comparado ao Monosyn ${ }^{\circledR}$ na sutura intradérmica de seis gatos. Observaram-se tempo de execução, avaliação clínica e microscópicas similares. Na avaliação clínica diária, ao longo de nove dias, não houve diferença estatística quando observado o período total, no qual todos os animais apresentaram apenas escores um e dois, sendo indicativo de ausência de reação visível e suave edema respectivamente. Porém, ao se avaliar cada dia, como por exemplo, no quarto dia de pós-operatório, notaram-se cinco animais do grupo Monosyn ${ }^{\circledR}$ com escore dois, enquanto no grupo polipropileno apenas um com o mesmo escore, evidenciando menor formação de edema. Na avaliação microscópica, os dois grupos foram caracterizados por moderada a severa celularidade, fato justificado pelo trauma tecidual provocado pela agulha, visto que as biópsias foram realizadas apenas após nove dias do procedimento cirúrgico. Entretanto, quando avaliado alinhamento de borda e epitelização o grupo com polipropileno mostrou-se mais eficiente. Por ser inabsorvível o fio de polipropileno, teve que ser removido (PAPAZOGLOU et al., 2010).

\section{FIOS FARPADOS}

O processo de fabricação consiste em cortes em sentido único ou oposto e incompletos no diâmetro dos fios lisos como, polipropileno, poligliconato, polidioxanona e poliglecaprone formando assim várias "flechas" ao longo do comprimento (Figura 10). Assim sendo, objetiva-se aumentar a superfície de contato 
com a ferida, garantir mais pontos de fixação e, consequentemente, evitar os nós (GREENBERG \& GOLDMAN, 2013).

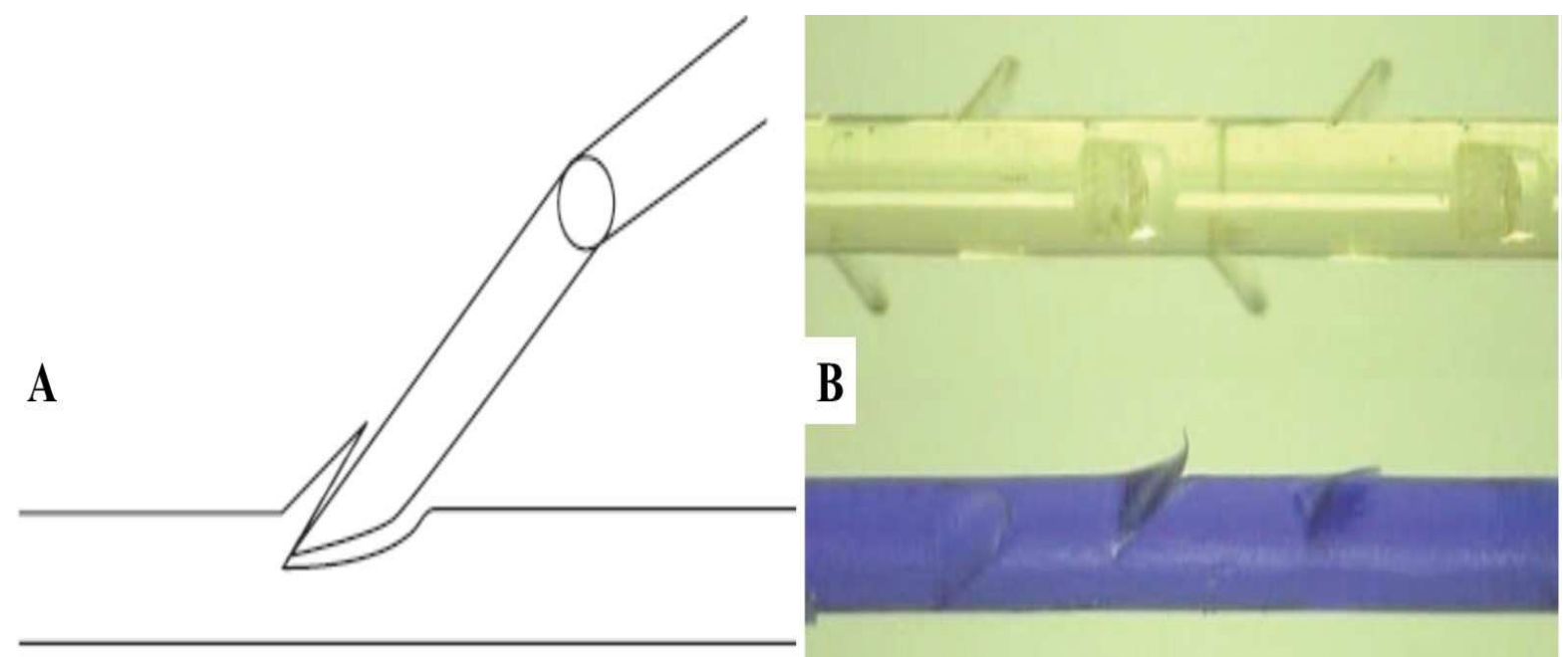

FIGURA 10- Fios farpados. A- ilustração do procedimento de fabricação. B- fio V-loc (amarelo), fio Quill Knotless (azul).

Fonte: adaptado do GREENBERG \& GOLDMAN, (2013).

A primeira patente foi concedida para o idealizador do fio farpado em 1964 (ALCAMO, 1964). Sendo que o primeiro relato ocorreu três anos após, com a utilização em cadáveres de humanos e "in vivo" em cães para a reparação de lesões em tendões flexores (MCKENZIE, 1967). Apesar de inovador e promissor por si só, os fios farpados tiveram a adesão acelerada, motivada, pelo reconhecimento das desvantagens dos nós e principalmente após a verificação do desafio de confeccioná-los de maneira rápida e segura, em procedimentos laparoscópicos. Dessa forma os nós, considerados mau necessário passaram a ser incriminados pelas desvantagens: redução da força tênsil do biomaterial em 35-90\%, proporcionada pela redução do diâmetro do fio; concentração da força tênsil em apenas um ponto (CHU et al., 1997); aglomeração de material, propiciando maior reação de corpo estranho e potencial a desatar (VAN RIJSSEL et al., 1989). Além de que o nó depende extremamente da técnica do cirurgião, não podendo ser muito apertado, o que acarreta hipóxia, isquemia, necrose, redução da proliferação de fibroblastos e deiscência, e nem muito frouxo comprometendo a estabilização da ferida (STONE et al., 1986) (Figura 11). Nesse cenário o primeiro modelo de fio farpado foi desenvolvido, em escala comercial, e aprovado pelo FDA apenas em 2004. Ainda assim com ressalvas devido à falta de estudos que comprovassem a segurança do implante em suturas para fechamento de fáscias (GREENBERG \& GOLDMAN, 2013). 


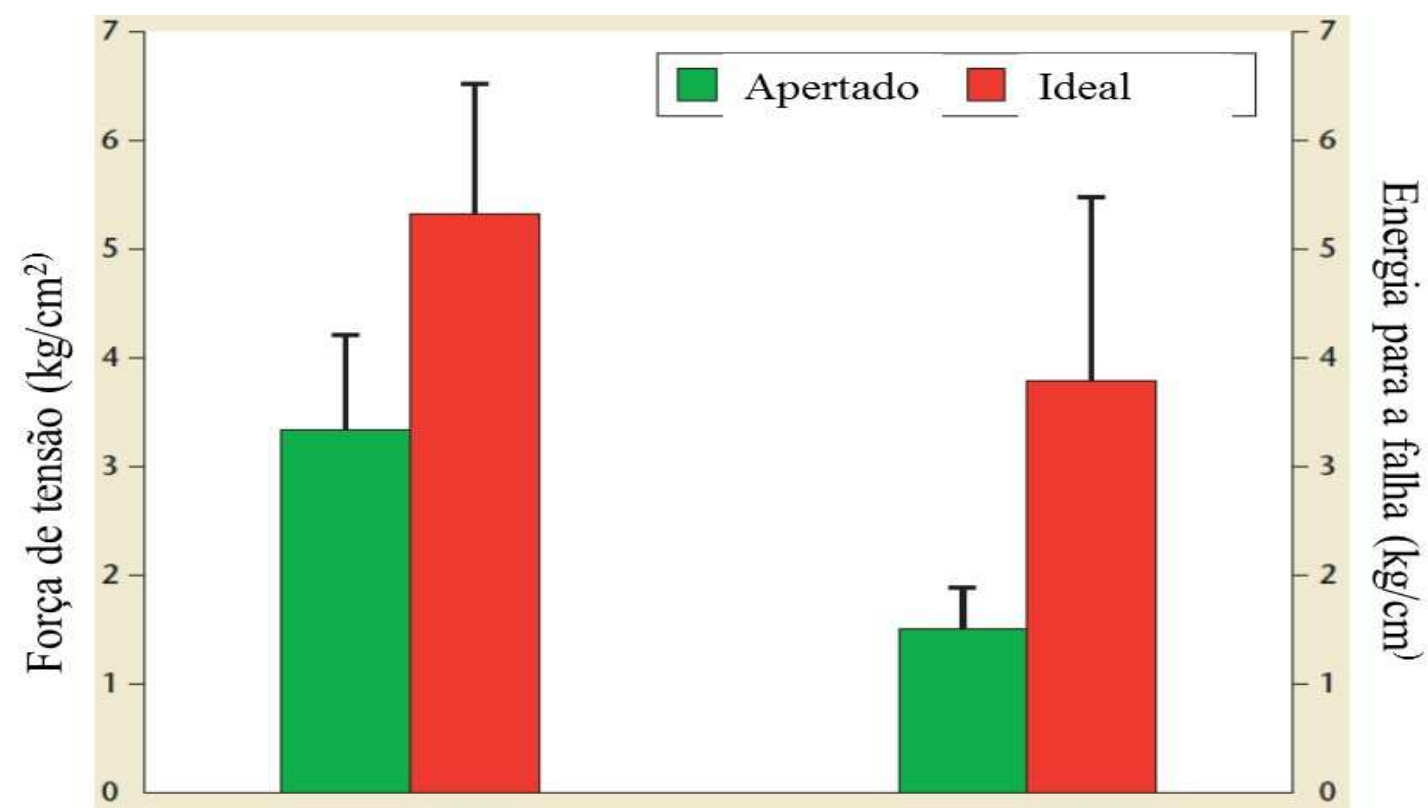

FIGURA 11- Força de tensão e energia para a quebra da força da ferida de fáscia do músculo reto do abdômem de ratos após 7 dias de pós operatório. Verde- aproximação com extrema tensão, apertado. Vermelho - aproximação com folga de $3,14 \mathrm{~mm}$.

Fonte: adaptado de STONE et al., (1986).

É conhecido que o processo de fabricação do fio farpado promove uma redução no seu diâmetro e consequentemente redução da força tênsil do fio. Dessa forma um estudo comparativo entre a resistência do fio farpado e liso mostrou que o primeiro tem resistência similar, apenas quando acrescido em uma a duas numerações USP que o segundo (VAKIL et al., 2011). Utilizando esse princípio, considerou-see que a força de distração necessária para quebrar a força de tensão de uma sutura de gastrotomia em cães foi maior quando realizaram com fios farpados. Ficou evidente ainda que no momento da quebra ocorria a ruptura dos tecidos e não a fratura dos fios. Concluiu-se então que a força de distração da ferida foi maior em casos de fios farpado graças a maior distribuição da força ao longo da ferida (ARBAUGH et al., 2013). Outra vantagem observada foi a maior resistência ao extravasamento de urina da vesícula urinária de suínos submetidos a cistorrafia com suturas contínuas farpadas quando comparada a sutura no padrão contínuo com fio liso. O primeiro resistiu ao extravasamento até a pressão causada com 419,7 mL, já o segundo, apenas, até 353,8mL (GÖZEN et al., 2012).

Adicionalmente o fio farpado garante maior agilidade nos procedimentos de síntese. Sendo assim, observou-se que a velocidade da cistorrafia laparoscópica em suínos realizada com fio farpado foi cerca de $22 \%$ mais rápida do que a realizada por sutura contínua com fio liso (GÖZEN et al., 2012). Essa redução no tempo cirúrgico resultou em menores perdas sanguíneas transcirúrgicas e menores custos, quando incorporados ao custo por minuto do centro cirúrgico (SMITH et al., 2014). Além disso, a qualidade da cicatrização foi testada comparando-se as duas aparências do fio. Nesse âmbito, a cicatrização do útero de ovelhas após a sutura com fio lisos e dentados foi comparada quanto a formação de aderências 
(EINARSSON et al., 2011), celularidade e presença de tecido conjuntivo e mostrouse similar entre os dois tipos de sutura (EINARSSON et al., 2012).

Por outro lado, uma desvantagem foi observada em um estudo clínico, que utilizou fios de suturas farpados e lisos em artroplastia. Nessa pesquisa notouse que o emprego de fios farpados houve um número maior de complicações, seja discretas ou graves no momento da alta hospitalar (Tabela 4). Apesar das complicações não serem estatisticamente significativas, alguns cirurgiões sentiramse intimidados e retiraram a sutura do protocolo (SMITH et al., 2014).

TABELA 4- Comparativo do porcentual das complicações discretas e graves, no momento da alta hospitalar, entre os fios farpado e tradicional em humanos submetidos a procedimentos de artroplastia.

\begin{tabular}{lccc}
\hline Sutura & $\begin{array}{c}\text { № de } \\
\text { pacientes }\end{array}$ & $\begin{array}{c}\text { No de complicações } \\
(\%)\end{array}$ & Complicações \\
Tradicional & 36 & Discreta: $2(5,5 \%)$ & 1 sutura proeminente \\
& & Grave: $0(0 \%)$ & 1 infecção superficial \\
Farpado & 98 & Discreta: $8(8,2 \%)$ & 2 suturas proeminentes \\
& & Grave: $2(2,0 \%)$ & 6 infecção superficial \\
& $\mathrm{P}=0,45$ & $\mathrm{P}=0,48$ & \\
\hline
\end{tabular}

Fonte: adaptado de SMITH et al., (2014).

Atualmente os fios farpados são considerados uma opção segura, rápida e eficaz para os procedimentos ginecológicos, na bexiga ou no intestino. Comercialmente podem ser encontrados com os nomes Quill Knotless ${ }^{\circledR}$, V-Loc ${ }^{\circledR}$ e Stratafix ${ }^{\circledR}$, com custo médio de 91,93 dólares. (EINARSSON et al., 2012; GREENBERG \& GOLDMAN , 2013; SMITH et al., 2014).

\section{CONSIDERAÇÕES FINAIS}

Fazendo uma análise cuidadosa sobre os fios de sutura, verifica-se que os estudos científicos sobre o tema foram publicados em uma infinidade de artigos. Mas faltam informações quando necessário maior tempo de observação, maior número amostral e comparações entre fios de mesma classificação. Essas evidências tornam-se mais evidentes quando se avalia dados obtidos na Medicina veterinária. Nesse cenário, encontram-se avaliações com grande espaço amostral e assim com maior confiabilidade apenas em relatos de casos humanos, graças a compilação de dados de um conjunto de instituições ou hospitais.

Considerando que existe certa deficiência de informações sobre o comportamento dos fios de sutura nas diferentes espécies domésticas, nota-se que é de importância fundamental a realização de relatórios cirúrgicos padronizados e a interação interdisciplinar para diminuir, em parte, as dúvidas existentes. Desta forma, 
é imprescindível a conquista pelo pesquisador em todos os experimentos conduzidos com animais como modelo experimental. Esta conduta facilitaria o manejo e a identificação de alterações provocadas devido a especificidade de cada modelo. Fatos que além de melhorar a qualidade dos trabalhos, facilitariam a elaboração de estudos para criação de diretrizes temporais da utilização do melhor fio para cada situação.

Durante muito tempo os avanços relacionados aos fios de sutura tiveram crescimento letárgico, porém na última década com o ganho de popularidade dos fios farpados alavancou-se o desenvolvimento. O estudo e ensaios clínicos desses é hoje realidade e devido ao repertório de vantagens supõe-se utilização cada vez maior nos próximos anos, trazendo consigo possíveis complicações e contraindicações. Acrescente-se a possibilidade do uso crescente na Medicina Veterinária, à medida que o custo reduzir ou ocorrer o aumento da frequência das vídeocirurgias.

A semelhança dos fios farpados, talvez com o mesmo ímpeto, porém prejudicado devido a não fabricação em escala comercial, o fio de quitosana aparenta ter resultados promissores, necessitando mais estudos que garantam a segurança em diversos tecidos, e a incorporação de todo o potencial desse biomaterial quando em forma de fio.

A compreensão das classificações, origem, filamentos e absorção, bem como as influências em cada característica, seja ela de manuseio ou estrutural e na relação ferida/fio, facilita o estudo individualizado de cada biomaterial. Por sua vez, o entendimento, noção, sobre a velocidade de cicatrização, tipos de feridas e tensão dos diferentes tecidos, é imprescindível para orientar a escolha do implante adequado. Sendo considerado o fio ideal aquele que induz menor resposta tecidual, interferindo assim, o mínimo possível no processo de cicatrização. Desta forma a escolha pelo fio ideal deve ser pautada pelos estudos ao invés do costume e tradição de cada instituição ou cirurgião.

Além da utilização de um fio adequado, o processo de cicatrização de ferida sempre irá se beneficiar de uma cirurgia bem planejada, da técnica de sutura correta, habilidade do cirurgião e de um bom manejo pós-operatório. Cada um desses cinco pilares correspondem num menor ou maior porcentual de influência no sucesso de um determinado procedimento cirúrgico, a depender das variadas situações enfrentadas.

Por fim, a busca pela universalização do material de sutura, não parará. Ao contrário, será frequentemente renovada, fomentada, a cada descoberta de um possível precursor, análises de complicações causadas pelos já existentes, desenvolvimento de técnicas cirúrgicas ou novidade na compreensão do processo de cicatrização.

\section{REFERÊNCIAS}

ABI RACHED, R. S.; DE TOLEDO, B. E.; OKAMOTO, T. Reaction of the human gingival tissue to different suture materials used in periodontal surgery. Brazilian Dental Journal, v. 2, n.2, p. 103-111, 1992.

AHN, H. B.; SHIN, D. M.; ROH, M. S.; JEUNG, W. J.; PARK, W. C.; RHO, S. H. A comparison of 2-octyl cyanoacrylate adhesives versus conventional suture materials for eyelid wound closure in rabbits. Korean Journal Of Ophthalmology, v. 25, n.2, p. 121-127, 2011. 
ARBAUGH, M.; CASE, J. B.; MONNET, E. Biomechanical comparison of glycomer 631 and knotless for use in canine incisional gastropexy. Veterinary Surgery, v. 42, p. 205-209, 2013.

ATALLAH, F. A.; SILVA, R. S.; MESQUITA, M. L.; OLIVEIRA, A. L. A.; FRANÇA, T. N.; BRITO, M. F. Complicações pós cirúrgicas em cadelas submetidas a ovariohisterectomia no Rio de Janeiro. Revista Brasileira de Medicina Veterinária, v. 35, p.61-69, 2013.

BALLANTYNE, G.H. Intestinal suturing: review of the experimental foundations for traditional doctrines. Diseases of the Colon \& Rectum, v. 26, n.12, p.836-843, 1983.

BELLENGER, C. R. Sutures part I: The purpose of sutures and available suture materials. Compendium on Continuing Education for the Practising Veterinarian, v. 4, $1982.587 \mathrm{p}$.

BERNIS-FILHO; WOUTERS, F.; WOUTERS, A. B.; BERNIS, V. M. O.; LOPES, L. R.; ANDREOLLO, N. A. Estudo comparativo entre os fios de algodão, poliglactina e poliglecaprone nas anastomoses intestinais de cães. Arquivos Brasileiros de Cirurgia Digestiva, v. 26, p. 18-26. 2013.

BEZWADA, R. S.; JAMIOLKOWSKI, D. D.; LEE, I. Y.; AGARWAL, V.; PERSIVALE, J.; TRENKA-BENTHIN, S.; ERNETA, M.; SURYADEVARA, J.; YANG, A.; LIU, S. Monocryl suture, a new ultra pliable absorbable monofilament suture. Biomaterials, v. 16, p. $1141-1148,1995$.

BHARATHI, A.; DHARMA, R.; KOTE, S. A prospective randomized comparative study of Vicryl Rapide versus Chromic Catgut for episiotomy repair. Journal of Clinical and Diagnostic Research, v. 7, n.2, p. 326-330, 2013.

BOOTHE, H. W. JR. Fio de sutura, adesivos de tecidos, grampeadores e clipes hemostáticos. In: Slatter D. Manual de cirurgia de pequenos animais. $3^{a}$ edição. Manole, São Paulo, Barueri, Brasil, p. 235-244.2007.

BOOTHE, H. W. Selecting suture materials for small animal surgery. Compendium on Continuing Education for the Practising Veterinarian, v. 20, p. 155-163, 1998.

BRUCK, S. D. Biostability of materials and implants. Journal Of Long-Term Effects Of Medical Implants, v. 89, p. 106, 1991.

CHU CC, VON FRAUNHOFER JA. GREISLER HP. Wound closure biomaterials and devices. CRC Press, Boca Raton, Florida, USA, 1997.

$\mathrm{CHU}, \mathrm{C}$. C. Mechanical properties of suture materials: an important characterization. Annals Surgery, v. 193, p. 365, 1981.

CHU, C. C.; VON, FRAUNHOFER, J. A.; GREISLER, H. P. Wound closure biomaterials and devices. Florida: CRC Press, 1996. 
CRAIG, P. H. A biologic comparison of polyglactin 910 and polyglycolic acid synthetic absorbable sutures. Surgery, Gynecology \& Obstetrics, v. 141, 1975.

DERNELL, W.; HANARI, J. Surgical devices and wound healing. In: Harari J. The small animal practice. 2ª . ed. Medvet, Pennsylvania, Philadelphia, USA, p.349-376. 1993.

DUBAS, S. T.; WACHARANAD, S.; POTIYARAJ, P. Tunning of the antimicrobial activity of surgical sutures coated with silver nanoparticles. Colloids and surfaces. A, Physicochemical and engineering aspects, v. 380, n.1-3, p. 25-28, 2011.

EDMISTON, C.E.; SEABROOK, G. R.; GOHEEN, M. P.; KREPEL, C. J.; JOHNSON C. P.; LEWIS, B. D. Bacterial adherence to surgical sutures: can antibacterial-coated sutures reduce the risk of microbial contamination? Journal of the American College of Surgeons, v. 203, n.4, p. 481-489, 2006.

EINARSSON, J. I.; GRAZUL-BILSKA, A. T.; VONNAHME, K. A. Barbed vs standard suture: randomized singleblind comparison of adhesion formation and ease of use in an animal model. Journal of Minimally Invasive Gynecology, v. 18, p. 16-19, 2011.

EINARSSON, J. I.; VONNAHME, K. A.; SANDBERG, E. M.; GRAZUL-BILSKA, A. T. Barbed compared with standard suture: effects on cellular composition and proliferation of the healing wound in the ovine uterus. Acta Obstetricia et Gynecologica Scandinavica, v. 91, p. 613-619, 2012.

ELLISON, G. W. Cicatrização visceral e disturbios decorrentes da reparação. In: Bojrab MJ. Mecanismos da moléstia na cirurgia de pequenos animais. 2 ed. Manole São Paulo, São Paulo, Brasil, 1996.

FERREIRA, M. L. G.; CHAUDON, M. B. O.; ABÍLIO, E. J.; DE CARVALHO, E.C. Q.; JAMEL, N.; ROMÃO, M. A. P.; NUNES, V. A. Estudo comparativo entre os fios de ácido poliglicólico e poliglactina na ileocistoplastia em cães (Canis familiaris). Revista Brasileira de Ciência Veterinária, v. 12, n. 1/3, p. 84-88, 2005.

FREEMAN, L. J. Tissue reaction to suture material in the feline linea alba. Veterinary Surgery, v. 16, p. 440, 1987.

GALLUP, D. G. Opening and closing the abdomen and wound healing. In: Gershensen DMCS; DeCherney A. Operative Gynecology, $2^{a}$ ed. WB Saunders, Pennsylvania, Philadelphia, USA 2001.

GLICKMAN, G.N.; HARTWELL, G. R. Endodontic surgery. In: Ingle JI; Bakland LK; Baumgartner JC. Endodontics 6. 6ª ed DC Decker, Ontario, Toronto, Canadá, 2008.

GÖZEN, A. S.; ARSLAN, M.; SCHULZE, M.; RASSWEILER, J. Comparison of laparoscopic closure of the bladder with barbed polyglyconate versus polyglactin suture material in the pig bladder model: an experimental in vitro study. Journal of Endourology, v. 26, p. 732-736, 2012. 
GREENBERG, J. A.; GOLDMAN, R. H. Barbed suture: a review of the technology and clinical uses in obstetrics and gynecology. Journal of Obstetrics and Gynaecology, v. 6, n.3/4, 107-115, 2013.

GREENBERG, J.A.; CLARK R. M. Advances in suture material for obstetric and gynecologic surgery. Journal of Obstetrics and Gynaecology, v. 2, n.3, p.146-158, 2009.

GREENWALD, D.; SHUMWAY, S.; ALBEAR, P.; GOTTLIEB, L. Mechanical comparison of 10 suture materials before and after in vivo incubation. Journal of Surgical Research, v. 56, p. 372-377, 1994.

HASAN, J.; CRAWFORD, R. J.; IVANOVA, E. P. Antibacterial surfaces: the quest for a new generation of biomaterials. Trends in Biotechnology, v. 31, n.5, p. 295-304, 2013.

HERMANN, J. B. Tensile strength and knot security of surgical suture materials. The American Journal of Surgery, v. 37, p. 209, 1971.

HOLT, G. R; HOLT, J. E. Suture materials and techniques. Ear, Nose \&Throat Journal, v. 60, p. 23, 1981.

HOLZHEIMER, R. G. Adverse events of suture: possible interactions of biomaterials? European Journal of Medical Research, v. 10, p. 521-526, 2008.

HOSGOOD, G.; BURBA, D.J. Wound management and bandaging. In: McCurnin DM; editors. Clinical textbook for veterinary technicians. $4^{\mathrm{a}}$ ed. WB Saunders, Pennsylvania, Philadelphia, USA, 1998, 477 p.

HUAIXAN, L. N. Comparação entre as histerorrafias com fios de sutura dos tipos categute e quitosana: macroscópica, histoquímica e imuno-histoquímica. Dissertação. Brasília: Universidade de Brasília, Faculdade de Agronomia e Medicina Veterinária; 2013.

IMPARATO, E.; ASPESI, G.; ROVETTA, E. Surgical management and prevenition of vaginal vault prolapse. Surgery, Gynecology \& Obstetrics, v. 175, p. 233-37, 1992.

ISLAM, M. A.; JUYENA, N. S.; FERDOUSY, R. N.; MAMUN, M. A. A. Effects of differents suture patterns and materials on healing of incised skin wounds in cattle. Bangladesh Journal of Veterinary Medicine, v.31, p.27-37, 2014.

JAVED, F.; AL-ASKAR, M.; ALMAS, K.; ROMANOS, G. E.; AL-HEZAIMI, K. Tissue reactions to various suture materials used in oral surgical interventions. ISRN Dentistry, p. 1-6, 2012.

JIBORN, H.; AHONEN, J.; ZEDERFELDT, B. Healing of experimental colonic anastomoses: bursting strength of the colon after left colon resection and anastomosis. The American Journal of Surgery, v. 136, n.5, p. 587-594, 1978. 
JONES, K. F A.; ABRAMOWITCH, D.; MOALLI, P.A. Evidence against the need for permanent suture for graft placement at the time of abdominal sacral colopexy. American Urogynecologic Society 30 ${ }^{\text {th }}$ Annual Meeting, Hollywood, EUA 2009.

KAKOEI, S.; BAGHAEI, F.; DABIRI, S.; PARIROKH, M.; KAKOOEI, S. A comparative in vivo study of tissue reactions to four suturing materials. Iranian Endodontic Journal, v. 5, n.2, p. 69-73, 2010.

KATZ, S.; IZHAR, M.; MIRELMAN, D. Bacterial adherence to surgical sutures: a possible factor in suture induced infection. Annals of Surgery, v. 194, n.1, p.35-41, 1981.

KAZEMZADEH-NARBAT, M.; LAI, B. F. L; DING, C.; KIZHAKKEDATHU, J.N.; HANCOCK, R. E. W.; WANG, R. Multilayred coating on titanium for controlled release of antimicrobial peptides for the prevention of implant-associated infections. Biomaterials, v. 34, n.24, p. 5969-5977, 2013.

KIRPENSTEIJN, L.; MAARCHALKERWEERD R. J.; GAAG, I. VAN DER; KOOISTRA, H. S.; VAN SLUIJS, F. J. Comparison of three closure methods and incisions in healthy dogs. Veterinary Quarterly, v. 23, p. 67-70, 2001.

KUMAR, M. S. ; NATTA, S.; SHANKAR, G.; REDDY, S. H. K.; VISALAKSHI, D.; SESHIAH. Comparison between silk sutures and cyanoacrylate adhesive in human mucosa: a clinical and histological study. Journal of International Oral Health, v. 5, n.5 p.95-100, 2013.

LACERDA, A. A. O. Fios e suturas. In: Lacerda A. A. O. Técnicas cirúrgicas em pequenos animais. Elsevier, Rio de Janeiro, Rio de Janeiro, Brasil, 2013.

MALDONATO, F.; MUNOZ, L.; QUEZADA M; BRIONES M; URRUTIA P. Reacción tisular a materiales de sutura no absorbibles em piel de equinos. Archivos de Medicina Veterinaria, v. 38, 2006.

MASINI, B. D.; STINNER, D. J.; WATERMAN, S. M.; WENKE, J. C. Bacterial adherence to suture materials. Journal of Surgical Education, v. 68, n.2, p. 101104, 2011.

MCDONALD, N. J.; TORABINEJAD, M. Endodontic surgery. In: Walton RE; Torabinejad M. Principles and practice of endodontics. 3 ed. Saunders, Pennsylvania Philadelphia: USA, 2002.

MCKENZIE, A. R. Na experimental multiple barbed suture for the long flexor tendons of the palm and fingers: preliminary report. The Journal of Bone and Joint Surgery, v. 49B, p. 440-447, 1967.

MCLOUGHLIN, M. A. Complications of lower urinary tract surgery in small animals. The Veterinary Clinics of North America. Small Animal Practice, v. 41, p. 889913, 2011. 
METZ, S. A; CHEGINI, N.; MASTERSON, B. J. In vivo and in vitro degradation of monofilament absorbable sutures, PDS $^{\circledR}$ and Maxon ${ }^{\circledR}$. Biomaterials, v. 11, p. 41-45, 1990.

MOLEA, G.; SCHONAUER, F.; BIFULCO, G.; D'ANGELO, D. Comparative study on biocompatibility and absorption times of three absorbable monofilament suture materials (polydioxanone, policlecaprone 25, glycomer 631). British Journal of Plastic Surgery, v. 53, n.2, p. 137-141, 2000.

MONTENEGRO, R.; GODEIRO, J. R. G. Chitosan based suture - focusing on the real advantages of an outstanding biomaterial. Adv Chitin Sci, v. 14, p. 211-216, 2014.

MUFFLY, T.M.; BOYCE, J.; KIEWEG, S. L.; BONHAM, A. J. Tensile strength of a surgeon's or a square knot. Journal of Surgical Education, v. 67, n.4, p. 222-226, 2010.

NASCIMENTO, H. B.; ALMEIDA, E. L.; RIBEIRO, J. J. S.; SIQUEIRA-FILHO, R. S.; QUEIROZ, R. A.; WANDERLEY, G. G. Hidronefrose secundária a ováriosalpingohisterectomia em cadela. Ciência Veterinária nos Trópicos, v. 15, n.1/2/3, p. 65-71 2012.

NOMURA, L.M.; RIBAS-FILHO, J. M.; MALAFAIA, O.; DIETZ, U. A.; SKARE, T. L.; KUME, M. H. Processo cicatricial de sutura em ceco com os fios polipropilene, poliglecaprone 25 e glicomer 60 em ratos. Arquivos Brasileiros de Cirurgia Digestiva, v. 22, n. 2, p. 82-88, 2009.

PAPAZOGLOU, L. G.; TSIOLI, V.; PAPAIOANNOU, N.; GEORGIADIS, M.; SAVVAS, L.; PRASSINOS, N.; KOUTI, V.; BIKIARIA, D.; HADZIGIANNAKIS, C.; ZAVROS, N. Comparison of absorbable and nonabsorbable sutures for intradermal skin closure in cats. The Canadian Veterinary Journal, v. 51, p. 770-772, 2010.

PEACOCK, E. E. JR. Wound repair. $3^{\mathrm{a}}$ ed. WB Saunders; Pennsylvania, Philadelphia, USA, 1984.

PELSUE, D. H. Closure of canine median sternotomy: suture vs wire. Veterinary Surgery, v. 28, p. 402, 1999.

POLK, H. C. Principles of operative surgery. In: Townsend CM Jr; editor. Sabiston Textbook of Surgery: the biological basis of modern surgical practice. $16^{\underline{a}}$ ed. WB Saunders, Pennsylvania, Philadelphia, 2001.

POSTLETHWAIT, R. W. Polyglycolic acid surgical suture. Archives of Surgery v. 101, p. 149, 1970.

RATNER, B. H. A.; SCHOEN, F. J.; LEMONS, J. E. Biomaterials science: an introduction to materials in medicine. $2^{\mathrm{a}}$ ed. Elsevier, Londres, 2004.

RAY, J. A. Polydioxanone (PDS): a novel monofilament synthetic absorbable suture. Surgery, Gynecology \& Obstetrics, v. 153, p. 497, 1981. 
RODEHEAVER, G. T. Unique performance characteristics of Novafil. Surgery, Gynecology \& Obstetrics, v. 164, p. 230, 1987.

ROSA, C. G. Quitina e quitosana: Aspectos gerais de obtenção e aplicações. Monografia. Pelotas: Universidade Federal de Pelotas, Departamento de Ciências dos Alimentos; 2008.

ROSIN, E.; ROBINSON, G. M. Knot security of suture materials. Veterinary Surgery, v. 18, p. 269, 1989.

ROUSH, J. K. Biomateriais e implantes cirúrgicos. In: Slatter D. Manual de cirurgia de pequenos animais. 3aㅡ ed. Manole, São Paulo, Barueri, Brasil, 2007.

RUNK, A.; SHEILA, W.; ALLEN, W.; MAHAFFEY, E. A. Tissue reactivity to poliglecaprone 25 in the feline linea alba. Veterinary Surgery, v. 28, p. 466-471, 1999.

SANTOS FILHO, H. A. Macroscopic and Microscopic evaluation and videoendoscopic observation of the gastric sutures in dogs with polyglactin and polyglecaprone. Tese. Rio de Janeiro: Universidade Federal do Rio de Janeiro, 2004.

SANTOS, F. C.; CORREAA, T. P.; RAHAL, S. C.; CRESPILHO, A. M.; LOPES, M. D.; MAMPRIM, M. J. Complicações da esterilização cirúrgica de fêmeas caninas e felinas: revisão da literatura. Arquivo Brasileiro de Medicina Veterinária e Zootecnia, v. 16, n.1, p.8-18, 2009.

SCHULTE, W. Tissue adhesives in the oral cavity. Deutsche zahnärztliche Zeitschrift, v. 23, n.1, p. 68-69, 1968.

SERRANO, C.; GARCIA-FERNANDEZ, L.; FERNANDEZ-BLAZQUEZ, J. P.; BARBECK, M.; GHANAATI, S.; UNGER, R.; KIRKPATRICK, J.; ARZT, E.; FUNK, L.; TURON, P.; DEL CAMPO, A. Nanostructured medical sutures with antibacterial properties. Biomaterials, v. 52, p. 291-300, 2015.

SHARP, W. V. Suture resistance to infection. Surgery, v. 91, p. 405, 1982.

SILVERSTEIN, L. H.; KURTZMAN, G. M. A review of dental suturing for optimal softtissue management: compendium of continuing education in dentistry. Compendium of Continuing Education in Dentistry, v. 26, n.3, p. 163-209, 2005.

SMEAK, D.D.; WENDELBURG, K. L. Choosing suture materials for use in contaminated or infected wounds. Compendium of Continuing Education in Dentistry, v. 11, p. 467, 1989.

SMITH, E. L.; DISEGNA, S. T.; SHUKLA, P. Y.; MATZKIN, E. G. Barbed versus traditional sutures: closure time, cost and wound related outcomes in total joint arthroplasty. Journal of Arthroplasty, v. 29, p. 283-87, 2014. 
SRUGI, S.; ADAMSON, J. E. A comparative study of tendon suture materials in dogs. Plastic and Reconstructive Surgery, v. 50, p. 31, 1972.

STASHAK, T. S.; YTURRASPE, D. J. Considerations for selection of suture materials. Veterinary Surgery, v. 7, p. 48, 1978.

STONE, I. K.; VON FRAUNHOFER, J. A.; MASTERSON, B. J. The biomechanical effects of tight suture closure upon fascia. Surgery, Gynecology \& Obstetrics, v. 163, p. 448-452, 1986.

SWAIM, S. F. Surgery of Traumatized skin: management and reconstruction in the dog and cat. WB Saunders, Philadelphia, USA, 1980.

US PATENT. Alcamo, J. H. Surgical suture. US n. PI 3123077, 3 março 1964.

VAKIL, J. J.; O'REILLY, M. P.; SUTTER, E. G. Knee arthrotomy repair with a continuous barbed suture: a biomechanical study. Journal of Arthroplasty, v. 26, p. 710-713, 2011.

VAN RIJSSEL, E. J.; BRAND, R.; ADMIRAAL, C. Tissue reaction and surgical knots: the effect of suture size knot configuration, and knot volume. Obstetrics \& Gynecology International Journal, v. 74, p. 64-68, 1989.

VASTARDIS, S.; YUKNA, A. Gingival soft tissue abscess following subepithelial connective tissue graft for root coverage: report of three cases. Journal of Periodontology, v. 74, n.11, p. 1676-1681, 2003.

WALTON, M. Strength retention of chromic gut and monofilament synthetic absorbable suture materials in joint tissues. Clinical Orthopaedics and Related Research, v. 242, p. 303, 1989. 